\title{
Altered identity: fleeting colors and obscured surfaces in Van Gogh's Landscapes in Paris, Arles, and Saint-Rémy
}

Federica Pozzi ${ }^{*}{ }^{*} \mathbb{D}$, Elena Basso ${ }^{1}$ [D, Silvia A. Centeno ${ }^{1}$ [D, Louisa M. Smieska² ${ }^{2}$ Nobuko Shibayama', Roy Berns ${ }^{3}$, Megan Fontanella ${ }^{4}$ and Lena Stringari ${ }^{4}$

\begin{abstract}
The Thannhauser Collection of the Solomon R. Guggenheim Museum, New York, represents an important survey of European avant-garde art production during the late 19th and early 20th centuries. Among the works included in this collection are three paintings by Vincent van Gogh, namely Roadway with Underpass (1887), Landscape with Snow (1888), and Mountains at Saint-Rémy (1889). These examples each exhibit some degree of surface alteration, including fading of specific pigments and, in one case, a non-original, discolored varnish, resulting in obscured color and spatial relationships, as well as being the subject of questions regarding authenticity in the case of the two earlier pictures. Initial examination involved documentation of the brushwork, paint quality, and distribution of colors under magnification. Infrared (IR) and ultraviolet (UV) photography, as well as X-radiography, provided additional information on the surface coatings, the structure of the works, and their supports. Subsequently, an in-depth scientific investigation of the ground and paint layers, with a special focus on fading colors and altered surfaces, was carried out non-invasively with point and macro-X-ray fluorescence (XRF) spectroscopy, visible reflection spectroscopy, and multi-channel visible spectrum four-light imaging, followed by the analysis of cross sections and dispersed pigment samples by means of optical microscopy, transmission Fourier-transform infrared (FTIR) and Raman spectroscopies, and scanning electron microscopy coupled with energy-dispersive X-ray spectroscopy (SEM/EDS), as well as high-performance liquid chromatography with photodiode array detection (HPLC-PDA) and pyrolysis-gas chromatography/mass spectrometry (PyGC/MS). Results indicated that both the brushwork and artist's palette of all three paintings are consistent with data previously reported for other Van Gogh works and with pigments described in the artist's letters to his friends and his brother Theo. Most notably, evidence of biodeterioration and paint alteration phenomena was found on Roadway with Underpass, while specific pigments such as eosin red-historically sold as geranium lake-were detected in areas of Landscape with Snow and Mountains at Saint-Rémy that display severe fading. In addition to assisting the development of a suitable plan for the conservation of the 1887 painting, this study traces the progression of Van Gogh's practice over three years critical to his artistic development, discusses the historical context in which each masterpiece was created, identifies the range of materials and techniques used, and addresses authenticity questions by providing a comparison with results of scientific analysis from other similar works.
\end{abstract}

Keywords: Van Gogh, Painting, Ground, Palette, Surface degradation, Fading, Eosin, Biodeterioration, Authenticity

${ }^{*}$ Correspondence: federica.pozzi@metmuseum.org

${ }^{1}$ Department of Scientific Research, The Metropolitan Museum of Art, 1000 Fifth Avenue, New York, NY 10028, USA

Full list of author information is available at the end of the article

\section{Introduction}

The Thannhauser Collection of the Solomon R. Guggenheim Museum, New York, represents an important survey of European avant-garde art production during the late 19th and early 20th centuries. Among the works
Springer Open

(c) The Author(s) 2021. This article is licensed under a Creative Commons Attribution 4.0 International License, which permits use, sharing, adaptation, distribution and reproduction in any medium or format, as long as you give appropriate credit to the original author(s) and the source, provide a link to the Creative Commons licence, and indicate if changes were made. The images or other third party material in this article are included in the article's Creative Commons licence, unless indicated otherwise in a credit line to the material. If material is not included in the article's Creative Commons licence and your intended use is not permitted by statutory regulation or exceeds the permitted use, you will need to obtain permission directly from the copyright holder. To view a copy of this licence, visit http://creativeco mmons.org/licenses/by/4.0/. The Creative Commons Public Domain Dedication waiver (http://creativecommons.org/publicdomain/ zero/1.0/) applies to the data made available in this article, unless otherwise stated in a credit line to the data. 
included in this collection are three paintings by Vincent van Gogh (1853-1890) spanning the final three years of his life: Roadway with Underpass (around mid to late summer 1887; Fig. 1a), painted in Paris and reflecting the artist's encounters with French Impressionism and PostImpressionism; Landscape with Snow (February 1888; Fig. 1b), among the first paintings completed upon Van Gogh's arrival in Arles; and Mountains at Saint-Rémy (July 1889; Fig. 1c), executed during his convalescence at Saint-Paul-de Mausole in Saint-Rémy-de-Provence.

Several leading questions regarding the materials composition and related degradation processes determined the primary scope of this study. All three paintings exhibit some degree of surface alteration, including fading of certain red organic lake pigments-phenomena that are discussed and referenced below. Most notably, Landscape with Snow has lost some of the bold effects of Van Gogh's signature use of complementary colors, such as pink next to green and yellow adjacent to purple. The painting no longer retains its original, vibrant juxtapositions of hues due to the fading of photosensitive pigments. Under the microscope, bright pinks and purples can be observed through cracks in the surface. Likewise, Mountains at Saint-Rémy is characterized by an overall blue palette that appears to be missing some of the red hues. Moreover, Roadway with Underpass had a thick, discolored varnish that, until it was removed during a major conservation treatment in 2018, covered a thin, uneven, brownish-gray layer trapped in the troughs of impasto. Presumably applied to cover abraded areas from an earlier restoration, this layer penetrated regions of exposed ground, and saturation by the varnish accentuated its appearance. Overall, these coatings rendered the painting dark and brooding, closer to Van Gogh's earlier
Dutch period paintings, despite the brightly colored palette. Furthermore, the surface treatment and its subsequent degradation shifted the global tonality of the composition from cool to warm.

The use of red organic lake pigments by Van Gogh during different periods of his life and the impact of their permanence on many of his paintings has been widely assessed by numerous authors [1-10]. Among these red lake pigments, eosin red, commercially known as geranium lake and one of the most prone to fading, has been the focus of relatively recent studies aiming to elucidate the different factors that affect deterioration [11-13]. The darkening of lead chromate-based yellows is another phenomenon widely reported for Van Gogh works, such as the different versions of his iconic Sunflowers, which has been investigated both in samples removed from paintings and in model paint systems with the purpose to clarify the mechanism of degradation [14-17].

In addition to materials-related questions, the Guggenheim works pose outstanding issues regarding provenance and authenticity, largely due to the fact that the two earlier paintings appeared on the art market in Germany around the same time as the notorious 1928 controversy concerning Van Gogh forgeries, known as the Wacker affair [18-20]. In the sequence of events, Otto Wacker, an art dealer and former professional dancer, first came under investigation in 1928, when the art dealers Grete Ring and Walter Feilchenfeldt declared to be fakes the four pictures Wacker had lent to an exhibition at the Paul Cassirer gallery in Berlin. The number of questionable Van Gogh paintings originating with Wacker soon swelled to more than thirty. The police raided the studio of Otto's brother, Leonhard Wacker, a restorer, and found in progress studies after Van Gogh compositions,
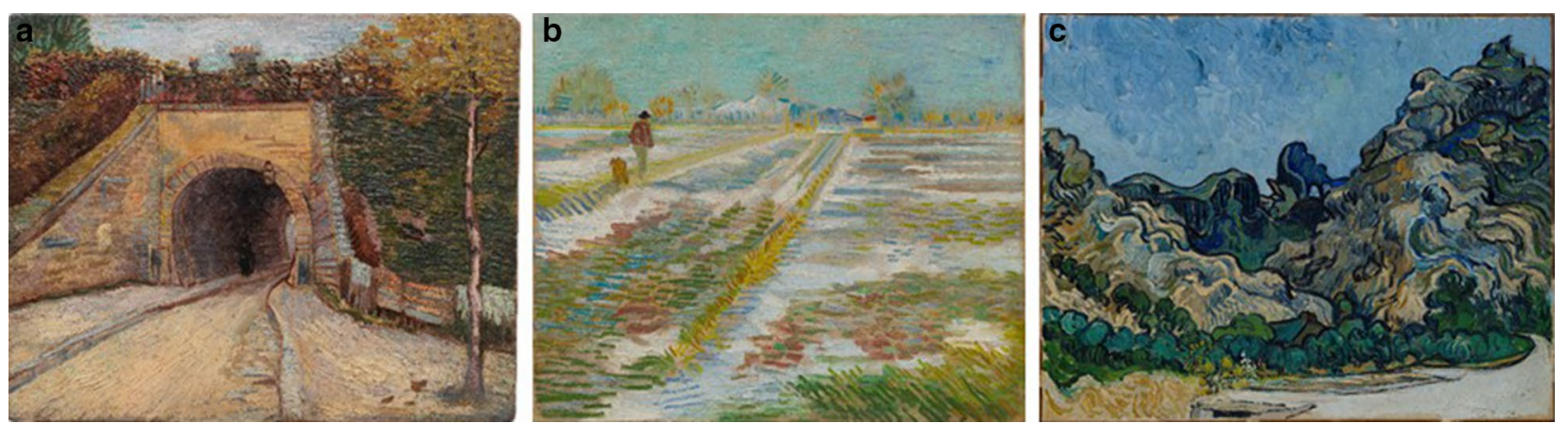

Fig. 1 Paintings by Vincent van Gogh analyzed in this study. a Roadway with Underpass (Le Viaduct), Asnières, 1887. Oil on cardboard, $127 / 8 \times 16$ 1/8 inches $(32.7 \times 41 \mathrm{~cm})$. Solomon R. Guggenheim Museum, New York, Thannhauser Collection, Gift, Justin K. Thannhauser 78.2514.17. b Landscape with Snow (Paysage Enneigé), Arles, February 1888. Oil on canvas, 15 1/16× $183 / 16$ inches $(38.2 \times 46.2 \mathrm{~cm})$. Solomon R. Guggenheim Museum, New York, Thannhauser Collection, Gift, Hilde Thannhauser 84.3239. c Mountains at Saint-Rémy (Montagnes à Saint-Rémy), Saint-Rémy-de-Provence, July 1889. Oil on canvas, $2811 / 16 \times 361 / 4$ inches $(72.8 \times 92 \mathrm{~cm})$. Solomon R. Guggenheim Museum, New York, Thannhauser Collection, Gift, Justin K. Thannhauser 78.2514.24 @ Solomon R. Guggenheim Foundation, New York 
although Leonhard never admitted his involvement in the forgeries that his brother Otto brought to market. At the time, scientific analysis and testimony solidified the case against Otto Wacker, who was charged with fraud. However, concerns and confusion remain over the methodologies employed and the designation of fakes associated with Wacker, though attempts have been made to document the pictures [21].

Roadway with Underpass and Landscape with Snow were not associated with Otto Wacker, but rather emerged as part of a group of six paintings (one of which is two-sided) that came to light in early 1927 . The other works were Head of a Peasant Woman (1884, Saint Louis Art Museum); Man and Woman Planting Potatoes (1885, Kunsthaus Zürich); Peasant Woman Sewing (1885, private collection); and The Potato Peeler (1885, The Metropolitan Museum of Art), which has on the reverse Self-Portrait with a Straw Hat (1887). Van Gogh connoisseur Jacob Baart de la Faille, who would soon publish the artist's catalogue raisonné, announced the discovery of these works in the German journal Der Cicerone, and declared the compositions "absolutely genuine and irreproachable" [22, 23]. The first public exhibition of the group occurred later in the year at the Galerie Hans Bammann in Dusseldorf. Around January 1928, the German art dealer Justin K. Thannhauser took all but one of this group of Van Gogh paintings on consignment from Bammann. By 1929, Justin's Galerie Thannhauser (which had branches in Berlin and Lucerne) had acquired the group in joint ownership with Richard Lohe Jr., a businessman from Wuppertal-Elberfeld [23, 24].

The early provenance of the Guggenheim paintings Roadway with Underpass and Landscape with Snow has also been linked to acquaintances of Van Gogh in Asnières (now Asnières-sur-Seine), a Parisian suburb that he frequented. In a letter to his brother Theo around May 20th, 1888, the artist indicated that he desired to give two paintings to the Levaillant de La Boissière family in Asnières; the artist had already given "her and her daughter" (Comtesse Clara and Eugénie Jeanne Levaillant de La Boissière) two paintings the year before [25]. No confirmation exists that Theo received the pictures, through Vincent's friend Christian Mourier-Petersen, or that he followed through on his brother's request to have them delivered to the Levaillant de La Boissière family; yet, this early provenance remains plausible. From this group of pictures that Thannhauser acquired in the late 1920s, Justin Thannhauser ultimately donated Roadway with Underpass to the Solomon R. Guggenheim Foundation, which owns and operates the museum, in 1978. Then, Thannhauser's widow, Hilde, gave Landscape with Snow to the Guggenheim in 1984. Justin Thannhauser likewise donated Mountains at Saint-Rémy, a work whose provenance and authenticity were not in question, to the Guggenheim in 1978, following a promised gift and extended loan.

In this context, an in-depth technical study of the three Van Gogh paintings at the Guggenheim involved visual documentation and scientific analysis of the surface coatings and degradation materials, ground and paint layers, brushwork and paint quality, distribution of colors, structure of the works, and their supports by means of a variety of instrumental techniques. This research aimed to trace the progression of Van Gogh's practice over three years as he moves from Paris to the South of France; to discuss the historical context in which the three masterpieces were created; to identify the materials and techniques used; and to compare the results of scientific analysis to data obtained from similar paintings by the artist as well as to his correspondence with friends and family. Special attention was devoted to the investigation of the current appearance of the works as a result of the fading of red organic lake pigments, alteration of surfaces, and ongoing degradation processes, as well as in relation to the paintings' treatment history, including early linings and cleaning interventions. Based on the results of pigment analysis and spectral reflectance measurements acquired across the surface, a digital reconstruction of Landscape with Snow was produced to provide viewers with a recolorized visualization of the appearance of this work prior to the fading of the original pink and purple tones. Notably, the comparative study of Van Gogh's materials was crucial to shed light on issues of authenticity concerning Roadway with Underpass and Landscape with Snow. In addition, the examination of the paintings' surfaces, as well as the analysis of cross sections and identification of various degradation issues, helped inform a suitable treatment strategy to clean the 1887 work.

\section{Experimental}

The campaign of technical examination and scientific analysis performed on Van Gogh's Roadway with Underpass, Landscape with Snow, and Mountains at SaintRémy relied on in-situ, non-invasive investigations with portable instruments and removal of microscopic samples followed by micro-invasive analysis with benchtop equipment in the Department of Scientific Research (DSR) of The Metropolitan Museum of Art (The Met). Initial inspection of the three paintings in the Guggenheim's conservation laboratory involved visual documentation of the brushwork, paint quality, and distribution of colors under magnification. Infrared (IR) and ultraviolet (UV) photography, as well as X-radiography, provided additional information on the surface coatings, the structure of the works, and their supports. Subsequently, 
non-invasive analyses using handheld X-ray fluorescence (XRF) spectroscopy, visible reflection spectroscopy, and multi-channel visible spectrum four-light imaging were carried out to gather information on the color palette in a selection of representative locations of the three works. After that, the paintings were transferred to The Met for macro-XRF (MA-XRF) analysis. Removal of fourteen microscopic scrapings and samples for cross sections led to examination with optical microscopy and micro-invasive analysis with a variety of instrumental techniques, including transmission Fourier-transform infrared (FTIR) and Raman spectroscopies, as well as scanning electron microscopy coupled with energy-dispersive $\mathrm{X}$-ray spectroscopy (SEM/EDS), with the main goal to identify the pigments, colorants, and extenders located in the ground and paint layers. Scrapings were also investigated with high-performance liquid chromatography with photodiode array detection (HPLC-PDA) and pyrolysis-gas chromatography/mass spectrometry (Py-GC/ MS) for a detailed characterization of some of the red lake pigments present in the paint mixtures, as well as the varnish and remnants of a brownish-gray material that covered the surface of Roadway with Underpass. Experimental conditions for the analytical techniques employed are reported below.

IR photography IR reflectography and transmittography were conducted using an Opus Instruments, Osiris shortwave IR (SWIR) imager, equipped with an InGaAs detector with sensitivity in the $900-1700 \mathrm{~nm}$ range. An 850-nm long-pass IR filter was used with a Rodagon $150 \mathrm{~mm} \mathrm{f} / 5.6$ lens, optimized for the IR region. The Osiris SWIR imager uses a linear 512-pixel sensor within a precision-geared mechanism that assembles a final $4096 \times 4096$ pixel image file. Images were post-processed and optimized within Adobe Photoshop.

UV photography UV-induced visible fluorescence photography was captured with a Sony Alpha 7RII mirrorless digital camera with Kodak Wratten 2E (UV-blocking) and Peca Products 918 (UV-IR-blocking) filters over the camera lens. The paintings were irradiated with two UV Systems TripleBright II fixtures with low-pressure mercury fluorescent UVA lamps with a peak emission at $368 \mathrm{~nm}$, outfitted with longwave UV-pass filters. A UV Innovations Target-UV was used for white balance, and post-processing was performed in Adobe Lightroom following the Capture Workflow by UV Innovations.

Multi-channel visible spectrum four-light imaging Analysis was carried out for Landscape with Snow and for Mountains at Saint-Rémy. A multi-shot Sinar CTM dual-pass camera was used having a 48MP Dalsa charge-coupled device (CCD) area array sensor, rePro body, Sinaron HR 100 lens, and filter slider with cyan and yellow absorption filters each affixed with a visible bandpass filter. Four Broncolor strobes were positioned above, below, left side, and right side at $60^{\circ}$ relative to the normal angle. For each painting, thirty-two images were captured: four multi-shot multiplied by two filters multiplied by four light positions. Diffuse-colorimetric and surface-normal maps resulted following image processing [26-28].

Small-aperture visible reflection spectroscopy Analysis was carried out for Landscape with Snow using a X-Rite i1 Pro 1 spectrophotometer that samples the visible spectrum from $380 \mathrm{~nm}$ through $730 \mathrm{~nm}$ at $10-\mathrm{nm}$ interval and bandpass and a $3.5-\mathrm{mm}$ circular aperture.

$X$-radiography Radiography was carried out using a Picker Hotshot AXR X-ray system by Associated X-Ray Corporation. Images were captured at $45 \mathrm{kV}, 3 \mathrm{~mA}$, and $90 \mathrm{~s}$ for Roadway with Underpass; $45 \mathrm{kV}, 3 \mathrm{~mA}$, and $45 \mathrm{~s}$ for Landscape with Snow; and $45 \mathrm{kV}, 3 \mathrm{~mA}$, and $55 \mathrm{~s}$ for Mountains at Saint-Rémy. Captures were digitized and stitched at the Northeast Document Conservation Center (NEDCC), using a GE model FS50B X-ray scanner. The scanner utilized GE Rhythm Acquire version 4.0 and Rhythm Review version 4.0 to capture and then process the files. Stitching and other post-processing work was performed with a combination of PTGui and Photoshop softwares.

Point XRF Analysis was performed using a handheld Bruker Tracer III- $\mathrm{V}^{\mathrm{TM}}$ energy dispersive XRF analyzer, with Peltier-cooled advanced high-resolution silverfree Si-PIN detector with a $0.2-\mu \mathrm{m}$ beryllium $(\mathrm{Be})$ window and average resolution of approximately $142 \mathrm{eV}$ for the full width at half maximum of the manganese $(\mathrm{Mn})$ $\mathrm{K} \alpha$ line. The system is equipped with changeable filters, and a rhodium $(\mathrm{Rh})$ transmission target with maximum voltage of $45 \mathrm{kV}$ and tunable beam current of 2-25 $\mu \mathrm{A}$. The size of the spot analyzed is approximately $3 \times 4 \mathrm{~mm}$. Analysis was performed using $40 \mathrm{kV}, 12.5 \mu \mathrm{A}, 120$-s acquisition time, and a titanium ( $\mathrm{Ti}$ )-aluminum (Al) filter, by positioning the instrument at $\mathrm{a} \approx 1-\mathrm{mm}$ distance from the artwork's surface.

$M A-X R F$ The three paintings were mapped using a Bruker M6 Jetstream ${ }^{\circledR}$ instrument with the X-ray source operated at $50 \mathrm{kV}$ and $0.5 \mathrm{~mA}$. A $700-\mu \mathrm{m}$ spot size and a 700- $\mu \mathrm{m}$ step size were used for the three works, with dwell times of 90, 100, and $120 \mathrm{~ms} /$ pixel for Mountains at Saint-Rémy, Landscape with Snow, and Roadway with 
Underpass, respectively. The spectra were processed using the Bruker M6 Jetstream ${ }^{\circledR}$ software.

FTIR Analysis was carried out in transmission mode with a Hyperion 3000 FTIR spectrometer equipped with a mercury cadmium telluride (MCT) detector. Each sample was crushed in a Spectra Tech diamond anvil cell and all the materials contained in it were analyzed as a bulk through a $15 \times$ objective. Spectra were collected in the $4000-600 \mathrm{~cm}^{-1}$ range, at a resolution of $4 \mathrm{~cm}^{-1}$, as the sum of 128 or 256 scans, depending on the response of each sample. Spectra were interpreted by comparison with published literature and library databases available at The Met's DSR.

Raman Analysis was conducted using a Bruker Senterra Raman spectrometer equipped with an Olympus $50 \times$ long working distance microscope objective and a CCD detector. A continuous wave diode laser, emitting light at $785 \mathrm{~nm}$, was used as the excitation source, and two holographic gratings (1800 and 1200 rulings $/ \mathrm{mm}$ ) provided a spectral resolution of $3-5 \mathrm{~cm}^{-1}$. The output laser power was kept between 10 and $25 \mathrm{~mW}$, while the number of scans and integration time were adjusted to prevent damage from overheating and according to the Raman response of the samples examined. Spectra were interpreted by comparison with published literature and library databases available at The Met's DSR.

SEM/EDS Samples for SEM/EDS analysis were mounted as cross sections in methyl methacrylate resin (Technovit ${ }^{\circledR} 2000 \mathrm{LC}$ ), cured under UV light for $20 \mathrm{~min}$, then polished using Micro-mesh ${ }^{\circledR}$ cloths to expose the stratigraphy. Analysis was carried out with a FE-SEM Zeiss Sigma HD equipped with an Oxford Instrument $\mathrm{X}$-MaxN 80 silicon drift detector (SDD). Back-scattered electron (BSE) imaging, as well as EDS elemental spot analysis and mapping, were performed in high vacuum with an accelerating voltage of $20 \mathrm{kV}$, on $12-\mathrm{nm}$ carboncoated samples.

HPLC-PDA The sample was placed in a $0.3-\mathrm{mL}$ conical vial, and $20 \mu \mathrm{L}$ of a mixture of methanol, acetonitrile, and pyridine $(1 / 1 / 1, \mathrm{v} / \mathrm{v} / \mathrm{v})$ was added and ultrasonicated for 15 min. $60 \mu \mathrm{L}$ of $8 \mathrm{~N}$ aqueous hydrochloric acid was added to the vial and heated at $90-100^{\circ} \mathrm{C}$ for $10 \mathrm{~min}$ [29]. The solution was evaporated under a gentle $\mathrm{N}_{2}$ stream. Subsequently, $10 \mu \mathrm{L}$ of methanol and $10 \mu \mathrm{L}$ of $0.01 \mathrm{M}$ aqueous oxalic acid (the latter acting as a chelating agent for any metal elements) were thus added, the solution was stirred and dried under $\mathrm{N}_{2}$ stream. $20 \mu \mathrm{L}$ of methanol were added again to the vial and the solution was placed under $\mathrm{N}_{2}$ stream to evaporate the acid further; the same procedure was repeated once again. In order to account for the possible presence of indigotin, $2 \mu \mathrm{L}$ of dimethylformamide were then added and heated at $50-60^{\circ} \mathrm{C}$ for a few min, after which $7 \mu \mathrm{L}$ of $1 \%$ aqueous formic acid and $9 \mu \mathrm{L}$ of methanol were also added to the vial. The solution was then centrifuged at $3500 \mathrm{~g}$ for $10 \mathrm{~min}$, and the supernatant injected into the HPLC system. The analytical system used consisted of a 1525 micro binary HPLC pump, 2996 PDA detector, 1500 series column heater, in-line degasser, and a Rheodyne 7725i manual injector with 20- $\mu$ l loop (Waters Corporation, Milford, Massachusetts). An XBridge BEH Shield RP18 reversephase column $(3.5-\mu \mathrm{m}$ particle, $2.1-\mathrm{mm}$ I.D. $\times 150 \mathrm{~mm})$ equipped with an XBridge BEH Shield RP18 guard column (3.5- $\mu \mathrm{m}$ particle, $2.1-\mathrm{mm}$ I.D. $\times 5 \mathrm{~mm}$ ) (Waters Corporation, Milford, Massachusetts) was used with a flow rate of $0.2 \mathrm{~mL} / \mathrm{min}$. An Upchurch ultra-low volume precolumn filter with a $0.5-\mu \mathrm{m}$ stainless steel frit (SigmaAldrich, St. Louis, Missouri) was attached in front of the guard column. The column temperature was set to $40^{\circ} \mathrm{C}$. The mobile phase was eluted in a gradient mode of (A) $1 \%$ formic acid in high purity water and (B) a mixture of methanol and acetonitrile $(1 / 1, \mathrm{v} / \mathrm{v})$. The solvent gradient was as follows: $90 \%$ (A) for $3 \mathrm{~min}, 90-60 \%$ (A) in $7 \mathrm{~min}$ in a linear slope, $60-0 \%$ (A) in $24 \mathrm{~min}$ in a linear slope, 0-90\% (A) in $1 \mathrm{~min}$, and then held at 90\% (A) for $10 \mathrm{~min}$. The eosin Y standard (Sigma, St. Louis, Missouri) was dissolved in a mixture of methanol and water $(1 / 1, v / v)$ prior to injection into the HPLC system.

Py-GC/MS Analysis was conducted on an Agilent 5973N gas chromatograph equipped with a Frontier PY-2020iD Double-Shot vertical furnace pyrolyzer fitted with an AS1020 E Auto-Shot autosampler. The GC was coupled to a 5973N single quadrupole mass selective detector (MSD). Samples of $30-50 \mu \mathrm{g}$ were weighed out in deactivated pyrolysis sample cups (PY1-EC80F Disposable Eco-Cup LF) on a Mettler Toledo UMX2 Ultra microbalance. Samples were then either pyrolyzed without derivatization or derivatized with tetramethyl ammonium hydroxide (TMAH) before pyrolysis. Derivatization took place in the same cups as follows: $3-4 \mu \mathrm{l}$ of $25 \%$ TMAH in methanol (both from Fisher Scientific), depending on the sample size, were added directly to the sample in each cup with a $50-\mu \mathrm{L}$ syringe and, after $1 \mathrm{~min}$, loaded onto the autosampler. The interface to the $\mathrm{GC}$ was held at $320^{\circ} \mathrm{C}$ and purged with helium for $30 \mathrm{~s}$ before opening the valve to the GC column. The samples were then dropped into the furnace and pyrolyzed at $550^{\circ} \mathrm{C}$ for $30 \mathrm{~s}$. The pyrolysis products were transferred directly to a DB$5 \mathrm{MS}$ capillary column $(30 \mathrm{~m} \times 0.25 \mathrm{~mm} \times 1 \mu \mathrm{m})$ with the helium carrier gas set to a constant flow of $1.5 \mathrm{~mL} / \mathrm{min}$. Injection with a 30:1 split was used, in accordance with 
the sample size. The $\mathrm{GC}$ oven temperature program was: $40^{\circ} \mathrm{C}$ for $1 \mathrm{~min} ; 10^{\circ} \mathrm{C} / \mathrm{min}$ to $320^{\circ} \mathrm{C}$; isothermal for $1 \mathrm{~min}$. The Agilent 5973N MSD conditions were set as follows: transfer line at $320^{\circ} \mathrm{C}$, MS Quad $150^{\circ} \mathrm{C}$, MS Source $230^{\circ} \mathrm{C}$, electron multiplier at approximately $1770 \mathrm{~V}$; scan range 33-550 amu. For samples run with TMAH, the detector was turned off until $3 \mathrm{~min}$ to avoid saturation by excess of the derivatizing agent and solvent. Data analysis was performed on an Agilent MSD ChemStation D.02.00.275 software by comparison with the NIST 2005 spectral libraries.

\section{Results and discussion}

A summary of the results obtained from the technical examination and scientific analysis of the three Van Gogh paintings under study is reported in Table 1 . These data are presented and discussed in further detail in the following paragraphs.

\section{Roadway with Underpass (1887)}

Though residing in Paris in 1887, Van Gogh made frequent trips to the suburb of Asnières in order to paint in nature. He would typically stay at the family home of his friend Émile Bernard (1868-1941), a young painter he mentored. Roadway with Underpass (Fig. 1a) depicts one of the many now-extinct poternes, or underpass and tollhouse structures, that circled Paris and regulated entry into the city. The masonry structure of the tunnel and surrounding foliage in the painting are nearly identical to images on postcards that predate alterations made in the early 20th century. A woman walks in the shadows of the arched underpass, moving away from the viewer toward a glint of light on the other side. Above the railway bridge, chimney stacks peek out through the dense vegetation.

Popular exhibitions of the French Impressionists and Post-Impressionists, including the work of Paul Signac, Louis Anquetin, Paul Gauguin, and Bernard, greatly influenced Van Gogh's painting technique during this time. The contrasting creamy tawny impasto and chalky blue shadows on the road leading to the crumbling underpass are reminiscent of the heightened palette and divided brushstroke of the Impressionists. Moreover, the complementary colors found in the energetic dots and loose dashes that imply the movement of the foliage animated by the breeze on the embankment attest to Van Gogh's interpretation of Divisionist color theory. Although the painting has been historically associated with late summer or autumn, Roadway with Underpass is arguably more akin to earlier works, produced in spring and early summer 1887 , which are more typically landscapes and thickly painted with short, directional brushstrokes [30].
As mentioned in the Introduction, Roadway with Underpass is particularly interesting due to the fact that it is one of Van Gogh's works whose authenticity was previously questioned. The painting had emerged on the German market in early 1927 along with five other small works (one of which is two-sided), at a time when Van Gogh forgeries were being produced in great numbers. The artist's extant correspondence is often pivotal in documenting the creation or establishing the whereabouts of various works in his oeuvre, with the exception of the Paris period, when he was in close proximity to his brother and, thus, few letters were exchanged between them. Nonetheless, the absence of a reference to an artwork in the letters-or in this case, the lack of a firm identification regarding pictures reportedly left to the Levaillant de La Boissière family in Asnières-does not preclude a work's legitimacy [31]. To situate Roadway with Underpass within the artist's practice, its materials and techniques of execution were investigated, and the results compared with those reported for verified works created in the same place and on close dates. As discussed in the following, scientific analysis and technical examination confirmed the identification of materials known to be used by the artist at this time and characteristic marks of his hand, reinforcing the attribution [32].

Roadway with Underpass was executed on a 2-mm thick, laminated, standard-size carton with rounded corners, which would have been inexpensive and easy to carry en plein air. Van Gogh typically used carton with both smooth and coarse preparations; in this instance, the painting's preparation layer was found to be a characteristic two-layer ground. Furthermore, visual features and early photographs of Roadway with Underpass, in addition to Thannhauser gallery labels affixed to the reverse, suggest that the painting was already mounted on an auxiliary support of approximately 7-mm laminated cardboard by the late 1920s. A significant tear or bend in the main carton support at left of center may have been the motivation for the mounting, which would have rendered the painting more stable for transport. This attachment to a secondary support appears to have resulted in overall flattened impasto and abrasion of thinner areas of paint application.

Analysis of cross sections removed from this painting, namely VG1, VG3, and VG4 (Fig. 2, Additional file 1: Figure S1), revealed that the two-layer ground consists of a 10 to $20-\mu \mathrm{m}$ thick bottom layer, predominantly composed of calcium sulfate, along with traces of various silicates, lead white, and iron-rich compounds, and an upper layer, with a thickness ranging from 10 to $40 \mu \mathrm{m}$, containing primarily lead white. According to FTIR data obtained from sample S7, the latter is present in the form of a mixture of cerussite (lead carbonate) and hydrocerussite 


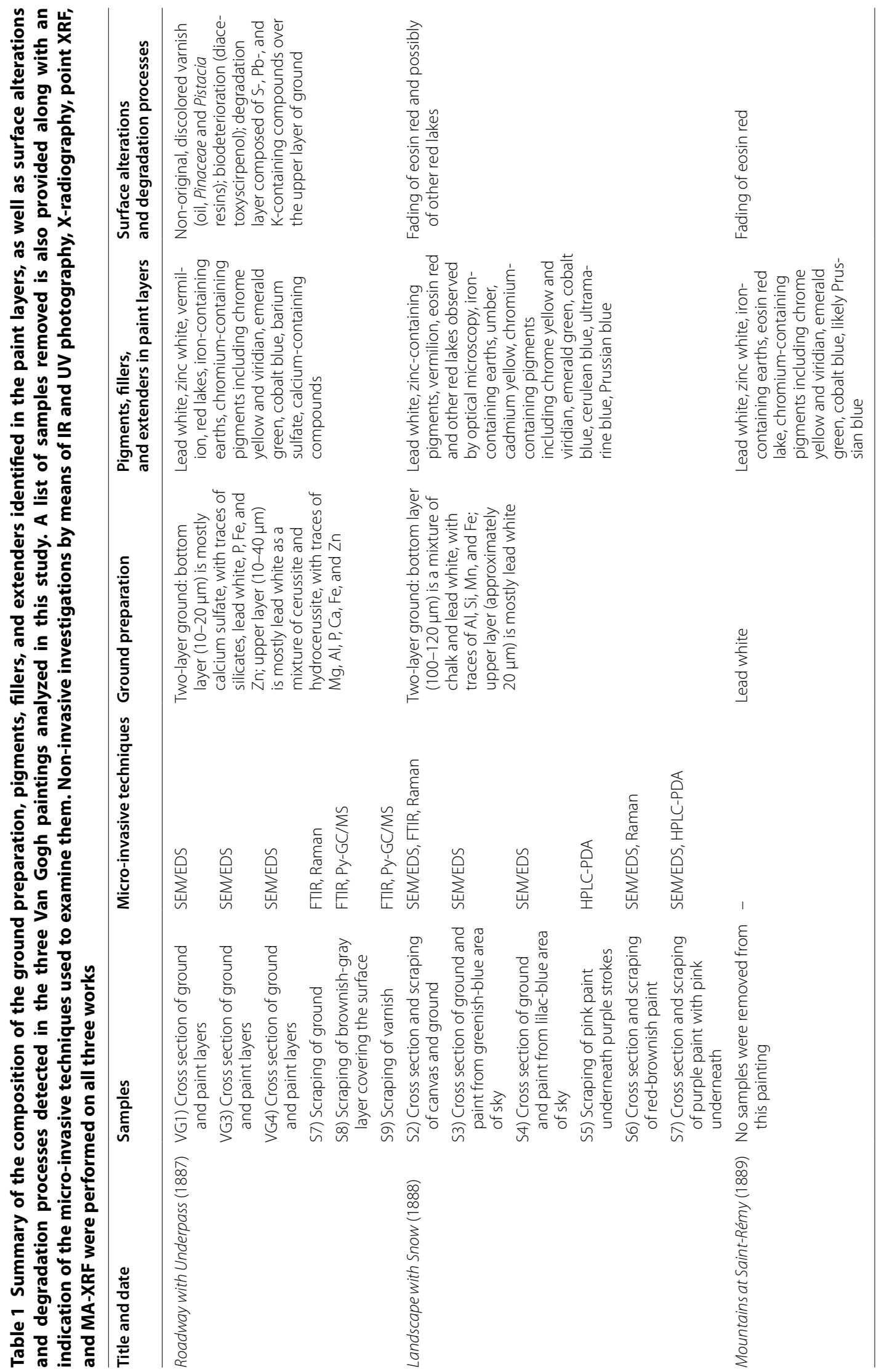


(basic lead carbonate), exhibiting distinctive bands at 1415, 1160, 1050, 966, 838, $680 \mathrm{~cm}^{-1}$ and 3534, 1415, $680 \mathrm{~cm}^{-1}$, respectively. Both layers in the ground contain relatively small amounts of iron and potassium (Additional file 2: Figure S2). Interestingly, based on visual examination under magnification, the lead whitecontaining layer appears to have been applied with a roller, which introduced a grainy texture, described as au grain in 19th-century texts. Application of thinned oil or washes over the ground further augments the grainy quality, creating a stippled effect that is evident on other works on carton by Van Gogh dating from 1887, namely Shoes (Van Gogh Museum, Amsterdam) and Self-Portrait (Kröller-Müller Museum, Otterlo).

In the BSE images of all three cross sections examined, an approximately 2- to $5-\mu \mathrm{m}$ thick gray layer is observed between the upper ground layer and the overlying paint (Fig. 2). X-ray elemental maps revealed that this layer is rich in sulfur, lead, and potassium (Additional file 2: Figure S2), and might originate from the migration of these elements from the ground and paint layers. In cross section VG4, sulfur, lead, and potassium also appear concentrated in a second location, below the uppermost paint layer, which is mostly composed of an iron-containing earth and lead white. Though this feature does not manifest itself in the BSE image to the same degree as does the layer that is located right over the ground, it is possible that both have similar origins. For fully assessing
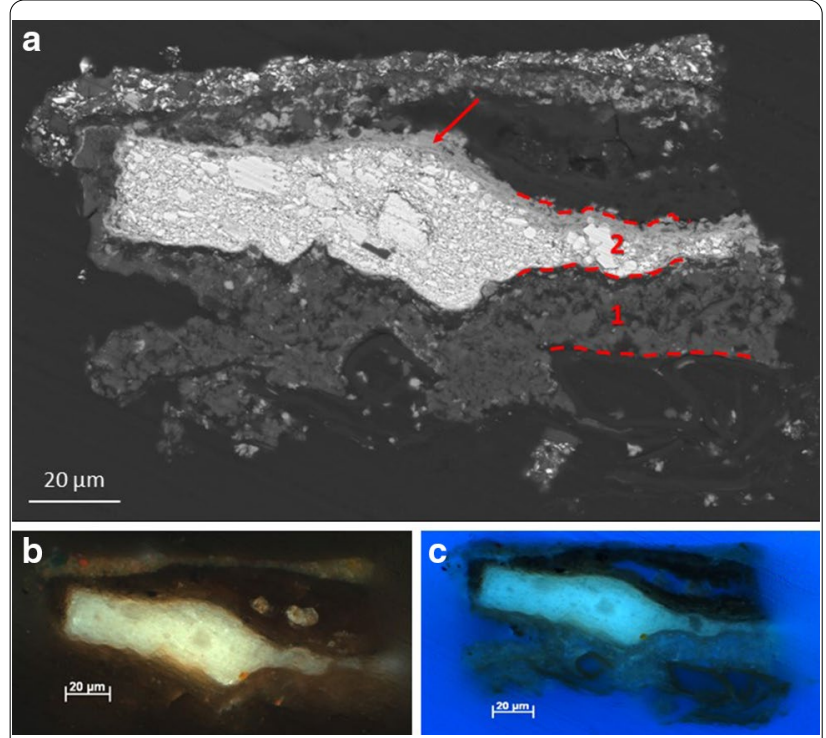

Fig. 2 a BSE image, b polarized light, and $\mathbf{c} U V$ light microphotographs of cross section VG4 from Roadway with Underpass, i.e. ground preparation and paint. In the BSE image, 1 and 2 indicate, respectively, the bottom and top layers of the ground preparation, while the red arrow shows the location of the sulfur-, lead-, and potassium-containing layer the origin of these layers, techniques that can detect and characterize all components localized in the paint stratigraphy with a high spatial resolution, such as X-ray diffraction combined with computed tomography (XRDCT) and other synchrotron methods, are necessary [33].

The quality of the paint in Roadway with Underpass, particularly in the foliage, is distinctive and lusciously applied. It flows in short, dense green and yellow strokes and in red, jellylike daubs, reminiscent of the fluid bold impasto and regular brushwork of the 19th-century French painter Adolphe Monticelli (1824-1886), whom Van Gogh especially admired. Throughout the composition, Van Gogh's pastose, painterly application and systematic parallel strokes, particularly evident in the foreground roadway, are juxtaposed to more irregular brushwork, thin transparent lines and glazes, and exposed priming in the interior of the tunnel and stone wall. Systematic and gelatinous dashes and dots of paint render the foliage dense and sumptuous. Some of the most unctuous brushstrokes describe leaves of green, yellow, and red, which were likely added later, during a reworking of the composition, as evidenced by their application over dry paint. An unidentified red pigment, which has the visual appearance of a lake, was used to sketch the outlines-a practice seen in a number of Van Gogh works from this period, as well as in Monticelli and various Post-Impressionist painters such as Paul Signac (1863-1935). The rather limited color palette, mostly construed through point and MA-XRF spectroscopy, consists of lead and zinc whites, iron-containing earths, chromium-containing pigments likely including chrome yellow and viridian, emerald green, cobalt blue, and vermilion (Fig. 3), in addition to barium sulfate and calcium-containing extenders (Table 1). Moreover, the lack of elements that may explain the color in some dark red and brown passages likely indicates the use of organic lake pigments such as madder or cochineal, which cannot be detected by XRF. These results align closely with pigments used in Van Gogh's other Paris works [32].

At this time, Van Gogh was known to frequently use a perspective frame when plotting out his landscapes. In the present work, however, no clear indication of the use of this device exists. Instead, beneath the image, dilute linear strokes of red lake are visible (Additional file 3: Figure S3), delineating the architecture and the angles of the roadway. The composition was originally defined with thin washes and thinned oil drawing lines. Some areas of the ground remained exposed, and sections of the masonry were left in reserve to establish the base color of the stone structure. Dilute red drawing can also be seen in other Paris period paintings, notably Montmartre: Windmills and Allotments (1887, Van Gogh Museum, Amsterdam). 

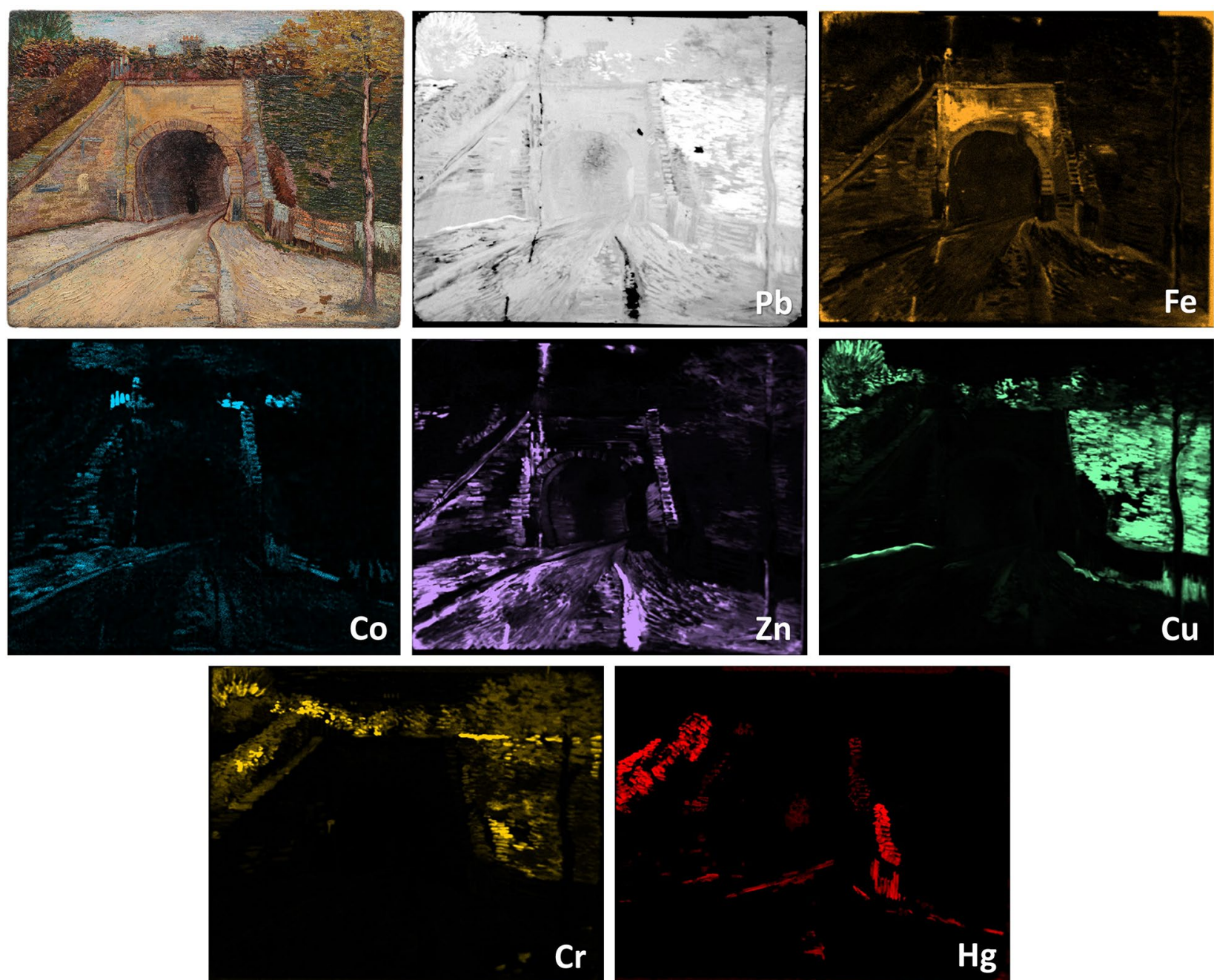

Fig. 3 Elemental distribution maps of Roadway with Underpass acquired by MA-XRF. From top left to bottom right: lead (Pb L $\beta$ ), iron (Fe Ka), cobalt (Co Ka), zinc (Zn Ka), copper (Cu Ka), chromium (Cr Ka), and mercury ( $\mathrm{Hg} \mathrm{La})$

From early in its existence, possibly also by the 1920s, the painting had a non-original, thick varnish that yellowed and darkened over time, presumably applied by a restorer, altering both the chromatic and spatial relationships of the composition. Py-GC/MS analysis of sample S9, i.e. a superficial scraping of the varnish, showed the presence of abietane-type compounds that are typical of diterpenoid natural resins belonging to the Pinaceae family, as well as 28-norolean-17-en-3-one, which is found in triterpenoid Pistacia resins such as mastic. In addition, glycerol and a series of fatty acids were detected, indicating the presence of an oil or a mixture of oils together with the resin. Oxidation of this varnish eventually caused the overall surface to appear dark and saturated, shifting the overall tonality from cool to warm. In addition, what appears as a brownish-gray, uneven coating on the surface below the varnish, combined with an earlier, aggressive treatment that left the surface with abrasions and the loss of thin touches of paint, is obscuring many of the colors and flattening the perspective. This murky layer penetrated the textured and absorbent ground, permanently leaving a stippled gray-brown tone in areas of exposed preparation. FTIR spectra of a scraping of this material (sample S8) showed bands attributable to a mixture of oil and natural resin. While it is possible that these are also part of the residue under examination, contamination from the adjacent varnish layer and/or the paint binder itself cannot be ruled out. In addition to lipids and resin components, chromatograms of this specimen revealed relatively high amounts of diacetoxyscirpenol. Also known as anguidine, this compound is a secondary metabolite product of fungi of the genus Fusarium that are widely distributed in soil and associated with plants, whose presence is indicative of biodeterioration $[34,35]$. 
One possible explanation of this result may lie in the fact that air-borne dirt and organic residues from the en plein air technique remained on the work's surface. Storage in high humidity conditions may have then contributed to the biodeterioration of these materials over time. At the time of the early restoration, the painting may have been varnished without completely removing these extraneous surface residues, thus locking them beneath the thick varnish coating. Once the varnish was removed, the graybrown layer was no longer saturated by the coating and, therefore, did not compromise the overall appearance as it had previously. Having been determined to constitute a permanent alteration to the painting surface, conservators did not remove this layer.

In 2018, a cleaning treatment was devised, based on solvent testing and informed by the results of scientific analysis, in order to remove the non-original varnish. Preliminary results of the cleaning were striking; test sites revealed the artist's variegated, colorful palette and began to reassert correct spatial relationships. Upon completion of the treatment, Roadway with Underpass exhibited jewel-like cool tones and complementary color juxtapositions that place the painting significantly closer to what one would expect at this moment, amidst the milieu of Paris, when the artist's practice was radically changing from earlier Dutch-inspired monochromatic compositions into colorful reflections of his environment (Additional file 4: Figure S4). The treatment to remove the thick layer of brownish-yellow varnish unveiled the original texture and palette, as well as the intended spatial relationships. Most notably, the cleaning revealed vicinal complementary colors-bright greens next to reds, blues adjacent to orange- uncovering a palette that closely related to other works from the Paris period, further confirming the attribution. Van Gogh was, in his own words, "trying to render intense color and not a grey harmony" [36].

\section{Landscape with Snow (1888)}

Van Gogh left Paris in mid-February 1888 and headed south, seeking rejuvenation and inspiration in the colors and light of the Provençal countryside. Yet, as he stepped off the train in Arles, snow covered the ground. Undeterred, the artist immediately produced a number of oil studies of the southern French town and its inhabitants in a colorful palette. Among these, Landscape with Snow (Fig. 1b) depicts a field partially covered in snow, with a man and his dog walking toward farmhouses in the distance. Small in scale, this oil sketch may be one of the three studies the artist referred to in his early days in Arles, as reported by his brother Theo to their sister Willemien: "[Vincent] has arrived in Arles, and found $50 \mathrm{~cm}$ of snow there, which isn't exactly what he'd been expecting, but he writes that he has made three studies all the same, which he wouldn't have been able to do in Paris at this time. [...] I hope that the milder air will do him good" [37].

Landscape with Snow may have been inspired by the snowy scenes common to the Japanese prints the artist avidly collected, but it also follows conventions of 17th-century Dutch landscape painting in its gradation of color from dark greens and browns framing the foreground to blue sky in the distance, and through the diagonal recession of the road in the snowy landscape. However, unlike Dutch panoramas with their broad expanse of sky, the present work focuses on the terrain and is painted from a perspective that is immersed in the landscape, on the same plane as the blue-hatted man and bowlegged dog trudging along the path. Van Gogh's use of brushwork that changes direction to demarcate the rows in the field is reminiscent of his reed-pen drawings or croquis (a quick, freehand sketch) that display elaborate patterning and differentiation of markings to define form. Newly arrived in Arles, Van Gogh was exploring his own personal vision, embedding many influences, as he worked in an unfamiliar environment with new subjects to paint [30].

Similar to Roadway with Underpass, Landscape with Snow had the misfortune of emerging on the art market at a time when numerous Van Gogh fakes were being produced; therefore, an in-depth technical examination and scientific analysis was carried out, in this case as well, with the primary goal to uphold or challenge the work's authenticity.

The canvas support of Landscape with Snow was most likely transported as a commercially prepared linen canvas from Paris. The canvas has a plain open-weave linen structure. Based on the results of a software analysis applied to a high-resolution X-radiograph as part of the Thread Count Automation Project, the plain openweave has a warp thread count of $12.1 \mathrm{th} / \mathrm{cm}$ and a weft thread count of $10.2 \mathrm{th} / \mathrm{cm}$. A comparison of this canvas with View of a Butcher's Shop (1888, Van Gogh Museum, Amsterdam) indicated a strong correspondence in weave pattern and density. Both of these paintings were completed within days of Van Gogh's arrival in Arles [38]. IR photography of the verso revealed a stamp from one of Van Gogh's preferred Parisian colorman shops, Tasset et L'Hôte, hidden beneath an early lining canvas, further placing this painting in the period (Fig. 4).

The painting appears to have been rapidly executed on a commercially-primed coarse linen canvas with a two-layer ground, which was analyzed in five cross sections and scrapings, namely S2, S3, S4, S6, and S7 (Figs. 5 and 6, Additional file 5: Figure S5), by means of SEM/EDS, FTIR, and Raman spectroscopies. The bottom layer of the ground preparation is between 100 and 
$120-\mu \mathrm{m}$ thick, relatively thicker than the top layer, and is composed of a mixture of calcium carbonate, likely calcite, and lead white. Interestingly, this layer contains an abundance of shell remains from marine organisms, such as foraminifera tests and unspecified bivalve fragments, commonly found in marine carbonate rocks like limestone and chalk, and a few quartz grains. Foraminifera are single-celled marine organisms mostly characterized by a multi-chambered carbonate shell. Clearly visible in some of the BSE images collected (Fig. 5), such fossilized shells were identified based on their distinctive

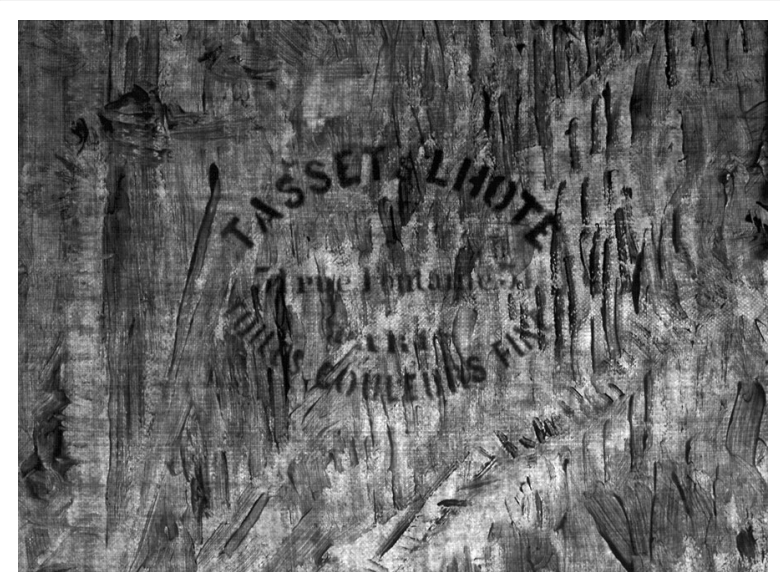

Fig. 4 IR reflectogram of verso of canvas for Landscape with Snow, detail of center right (rotated $90^{\circ}$ counterclockwise), showing the stamp for Van Gogh's preferred Parisian colorman, Tasset et L'Hôte morphology and elemental composition. The presence of foraminifera in ground layers consisting of natural chalk is not unusual [39-41], and mixtures of natural chalk with lead white in the ground preparation are quite common in Van Gogh's paintings [7, 9, 42, 43]. Besides lead and calcium, traces of aluminum, silicon, iron, and manganese were also detected in this bottom layer, which are likely indicative of sporadic silicate inclusions, as well as of iron-containing earths and umber pigments. The upper layer of the ground, approximately $20-\mu \mathrm{m}$ thick, is mostly composed of lead white in the form of tightly packed particles (Fig. 5). The identification of lead white was confirmed by Raman spectroscopy, due to the detection of a characteristic band at $1049 \mathrm{~cm}^{-1}$; analysis with FTIR enabled a more precise characterization of this material as hydrocerussite, while also highlighting the formation of lead carboxylates, likely originating upon reaction between the lead pigment with the oil medium (Additional file 6: Figure S6).

Van Gogh skillfully achieved the patchy coverage of the snow through linear dashes and thick strokes of impasto dragged in all directions across the surface, leaving large areas of bare ground exposed. Long white diagonal brushstrokes, which are visible under the bands of colored grasses in the field, indicate the composition's perspective, perhaps in lieu of an underdrawing. The graphite lines of a perspective frame could not be readily identified either with the naked eye or under magnification, although the artist claimed to have continued his use of this device, likely irregularly, until later that spring.
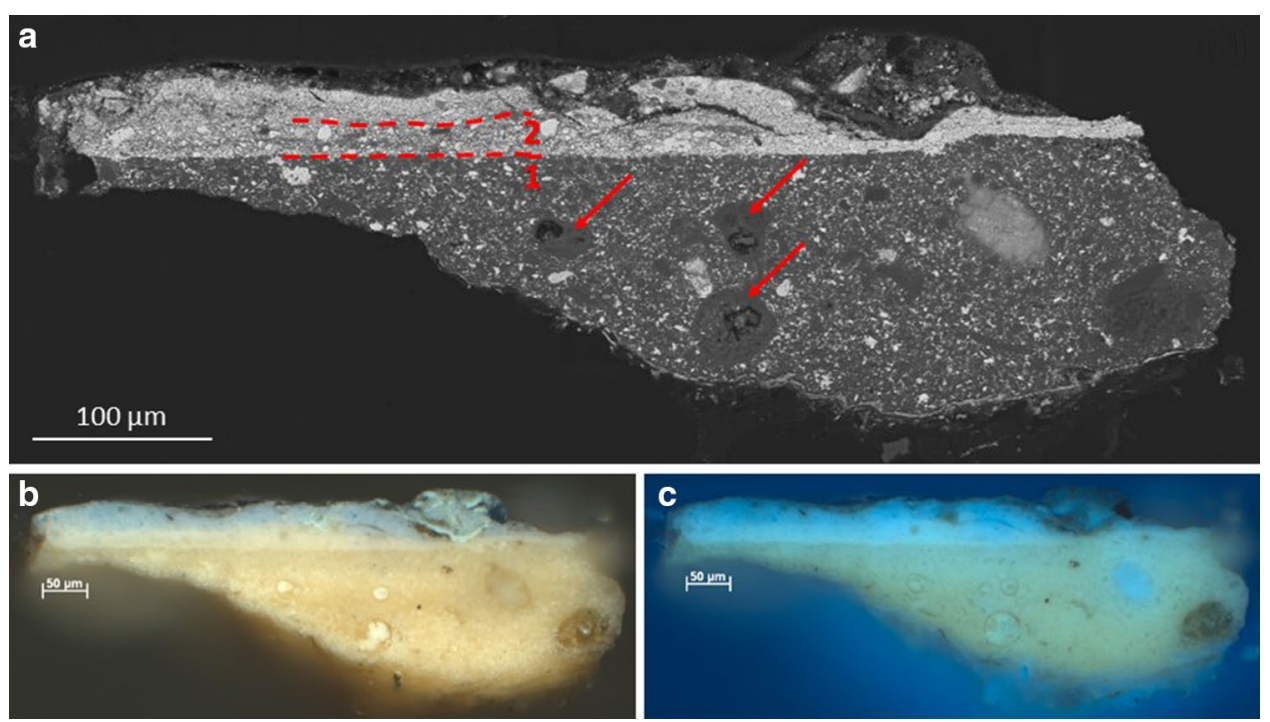

Fig. 5 a BSE image, b polarized light, and $\mathbf{c}$ UV light microphotographs of cross section S4 from Landscape with Snow, i.e. ground preparation and paint. In the BSE image, 1 and 2 indicate, respectively, the bottom and top layers of the ground preparation, while the red arrows show the location of the fossilized marine organisms 

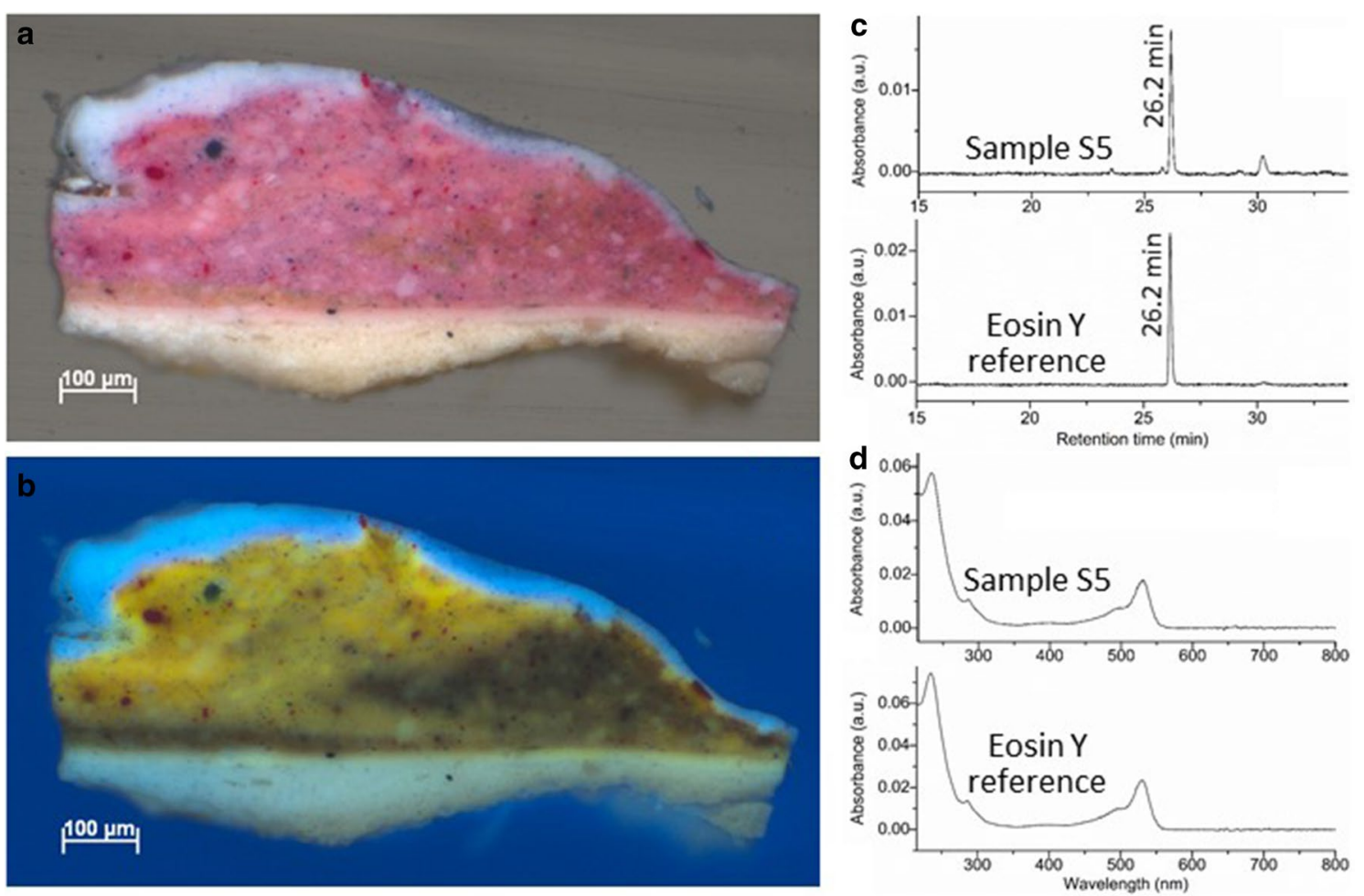

Fig. 6 a Polarized light and $\mathbf{b}$ UV light microphotographs of cross section S7 from Landscape with Snow, i.e. ground preparation and paint, revealing a bright pink layer with a yellow UV-induced autofluorescence, whose superficial portion likely faded upon exposure to light. c HPLC chromatogram of sample S5, i.e. a scraping of pink paint underneath some purple strokes in the field, compared to that of a reference eosin sample. $\mathbf{d}$ Visible spectrum of the main peak detected in the chromatogram of sample $\mathrm{S} 5$, compared to that of reference eosin

The palette of Landscape with Snow exhibits a full range of pigments, which, like the canvas, were most likely carried from Paris, given Van Gogh's difficulty in obtaining art supplies in the South of France and the fact that he created several works within days of his arrival. The main paint colors were analyzed non-invasively with point and MA-XRF (Additional file 7: Figure S7), and micro-invasively via Raman spectroscopy, HPLC-PDA, and SEM/ EDS examination of samples S3, S4, S5, S6, and S7 (Figs. 5 and 6, Additional file 5: Figure S5). In the field, long lead white strokes are broken up with lines of many different hues, including an unidentified turquoise blue that was not found to contain any cobalt; a lilac paint obtained as a mixture of lead white with eosin red, ultramarine blue and cobalt blue, as well as emerald green; reddish-brown iron-containing earths and umber pigments, whose presence was confirmed by prominent Raman bands at 226, $294,413,505,614 \mathrm{~cm}^{-1}$ and SEM/EDS analysis of cross section S6; two different greens-viridian and emerald green; and a range of yellows, including chrome and cadmium yellows. Among the latter shades, chrome yellow is predominant, while cadmium was only detected in very small amounts in some yellow and brown areas, as well as in the dog at left. Swiftly executed strokes describe the figure crossing the field with the animal in tow. Thickly painted, they both appear to have been reworked after the initial sketch was partially dry; for example, in the man's shirt, a red iron-rich earth tone covers an underlying blue-green color, while his dark blue hat contains iron as the only distinctive element (Additional file 7: Figure S7), likely indicative of Prussian blue. At the horizon line, select trees were left in reserve and the sky was painted around them, while others appear to have been painted wet-in-wet. Vermilion, as shown in the MA-XRF maps, was only used in the two roofs of the buildings in the background.

Special attention was devoted to the examination of the sky, whose color was initially believed to have possibly undergone some degree of alteration overtime, shifting from a more intense violet color to a light blue hue. Optical microscopy and SEM/EDS analysis of cross sections S3 and S4 (Figs. 5 and 7, Additional file 5: Figure S5) revealed that two shades of blue in the sky, one more greenish and one tending towards a lilac hue, were produced as mixtures of entirely different pigments. In detail, the light green color observed at far right, just 
above the trees on the horizon line, consists of emerald green and lead white, mixed in with several minute ultramarine blue and a few viridian particles, and covered by a thin lead white layer to convey a hazy effect. The second, lilac-blue shade is a mixture of lead white with cobalt and magnesium-rich cerulean blues, which appears even throughout the height of the paint layer and shows no evidence of fading. It is worth mentioning that in cross section S4, removed from the latter area of sky, the uppermost paint layer appears of a light blue color, and no red lake particles are visible in the paint mixture. As in the case of Roadway with Underpass, the pigments identified in this work correspond to those used in other Van Gogh paintings from his Paris period, and a number of them match those mentioned in a letter to his brother Theo from early April 1888, as he requested an order from Tasset et L'Hôte [44].

Some of the pink and violet colors in Landscape with Snow have lost their vibrancy due to the fading of lightsensitive organic lakes, as previously observed in works by Van Gogh and other artists of this period [1-10]. Technical examination and scientific analysis suggest that the painting, now conveying a peaceful melancholy, once had a much more lively, rosy early morning glow, which would have reflected the artist's sustained interest in complementary colors. Van Gogh wrote to Willemien in March 1888, shortly after his initial burst of productivity: "You understand that the countryside of the south can't exactly be painted with the palette of [Anton] Mauve, say, who belongs in the north and is and always will be the master of grey. But today's palette is definitely colorful-sky blue, pink, orange, vermilion, brilliant yellow, bright green, bright wine red, violet" [45].

Visual inspection by means of optical microscopy suggests that certain purples might have shifted from a warm magenta-violet to a significantly cooler bluish tone, select pinks have disappeared entirely, and the range of yellows would have been more variegated and brighter; for instance, in certain areas, chrome yellows may have undergone a degradation process, causing them to turn to a darker brownish tone. As the number of samples removed from the paintings in this study was limited to a minimum, however, the presence of lead chromate-based yellows was inferred from visual observations combined with XRF data and, therefore, it was not possible to determine the exact pigment types present. Brushstrokes that currently appear grayish or muddy were found to contain traces of pink and coarse bluish-green particles when viewed under magnification, perhaps indicating an earlier violet color. Bright pink and orange passages can be observed through some of the cracks, suggesting that the overall hues of the painting were originally more saturated and may have contained a range of red lakes. Interestingly, polarized light images of a cross section removed from an area of lilac paint in the field (sample S7) revealed, above the double ground, a 50 to $500-\mu \mathrm{m}$ thick, bright pink layer displaying a yellow UV-induced autofluorescence and whose white, superficial portion likely faded upon exposure to light (Fig. 6a, b). According to the EDS results (Additional file 8: Figure S8), this paint consists of a bromine-containing pigment, most likely eosin red, precipitated onto an aluminum-based substrate, and mixed with lead white, an abundance
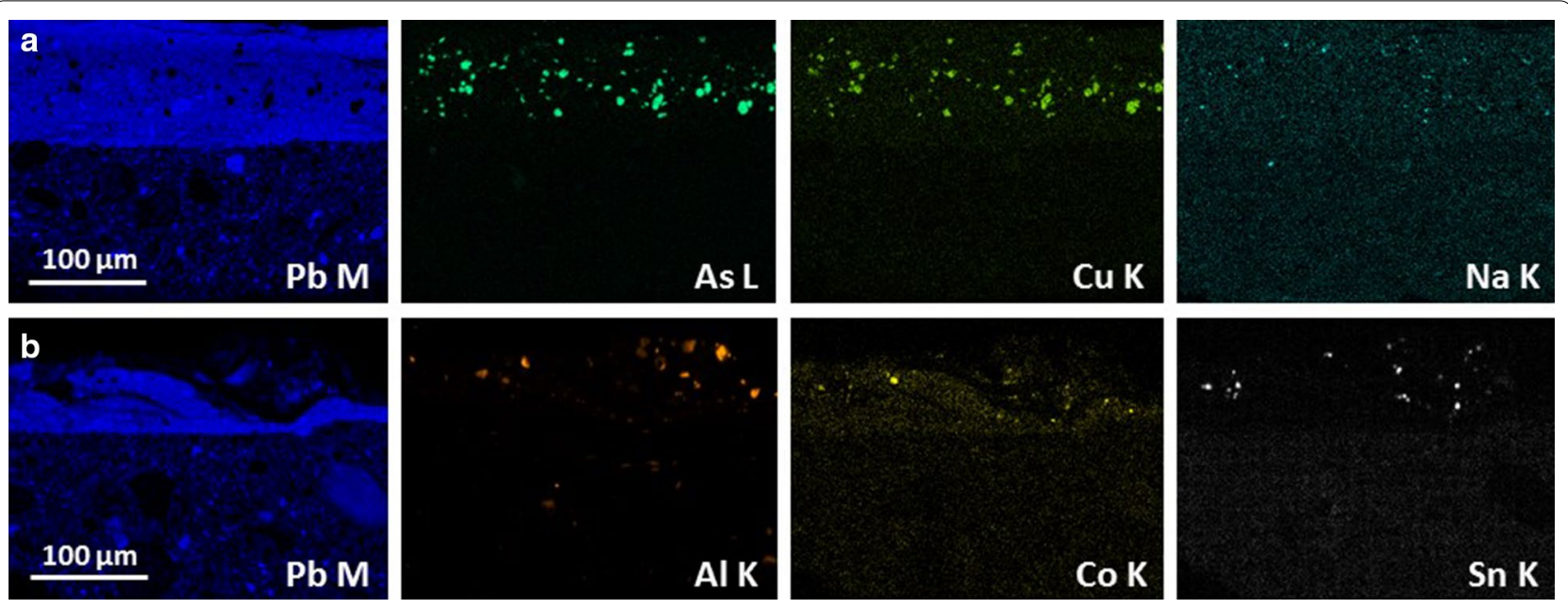

Fig. 7 X-ray elemental maps of two different blue paint samples taken from the sky of Landscape with Snow, as analyzed with SEM/EDS in a cross section S3, i.e. ground preparation and greenish-blue paint, suggesting the presence of lead white, emerald green, and ultramarine blue; and $\mathbf{b}$ cross section S4, i.e. ground preparation and lilac-blue paint, suggesting the presence of lead white, cobalt blue, and cerulean blue 
of minute ultramarine blue particles that appear to be homogeneously distributed across the sample's thickness, a few cobalt blue particles, and several emerald green grains mostly located in the right portion of the layer. The presence of eosin Y in Landscape with Snow was confirmed with HPLC-PDA analysis in sample S5 (Fig. 6c, d), i.e. a scraping of pink paint underneath some purple strokes in the field, near the proper right edge. Reportedly one of Van Gogh's favorite pigments, eosin has been widely used by the artist along with red lakes of natural origin, whose discoloration overtime has had a noticeable impact on several of his works [4-8].

The fading mechanism of eosin lake has been relatively recently investigated by Alvarez-Martin and coauthors, who proposed a primary photodegradation pathway for the colorant in linseed oil, and by Chieli, Miliani, Degano, and their team, who evaluated the role of the irradiation wavelength range, oxygen, and binder on the photochemistry of the pigment [11, 12]. In Landscape with Snow, as a result of this phenomenon, the juxtaposition of pinks and greens, or yellow adjacent to purple, no longer produces the same bold effects as in Van Gogh's lifetime, and the most significant relationships between these colors are now minimized. Small-aperture reflection spectroscopy was carried out on the pink and purple areas as well as the snow, assumed to represent the white used by Van Gogh, with the final goal to produce a digital recolorized visualization of the painting. A two-constant Kubelka-Munk database of common pigments employed by the artist [46] and the snow white were used to identify pigments that matched the absorption and scattering spectra of the pink and purple areas. The absorption and scattering spectra of eosin lake were added to the matched spectra at four concentrations. The changes in color were then used to create custom Photoshop adjustment curves, and image masks were made of these areas for the colorimetric diffuse map. The Guggenheim research team determined the two optimal adjustment curves based on their familiarity with Van Gogh's working method. Details of this experimental procedure are described in reference 46 . The current and recolored diffuse maps and the surface normal map were used to render images illuminated by a point source at an angle of $55^{\circ}$ from above the painting, selected to show brushwork without excessive shadows (Fig. 8) [27, 28]. The resulting reconstruction offers the viewer an approximation of the original appearance of the painting, prior to the fading of the pinks and purples [26, 47]. The same approach was also used to reconstruct The Art Institute of Chicago's The Bedroom [6]. As noted in his letters, Van Gogh was well aware of the inherent instability of some of his materials: "You were right to tell Tasset that the geranium lake should be included after all, he sent it, I've just checkedall the colors that Impressionism has made fashionable are unstable, all the more reason boldly to use them too raw, time will only soften them too much" [48].
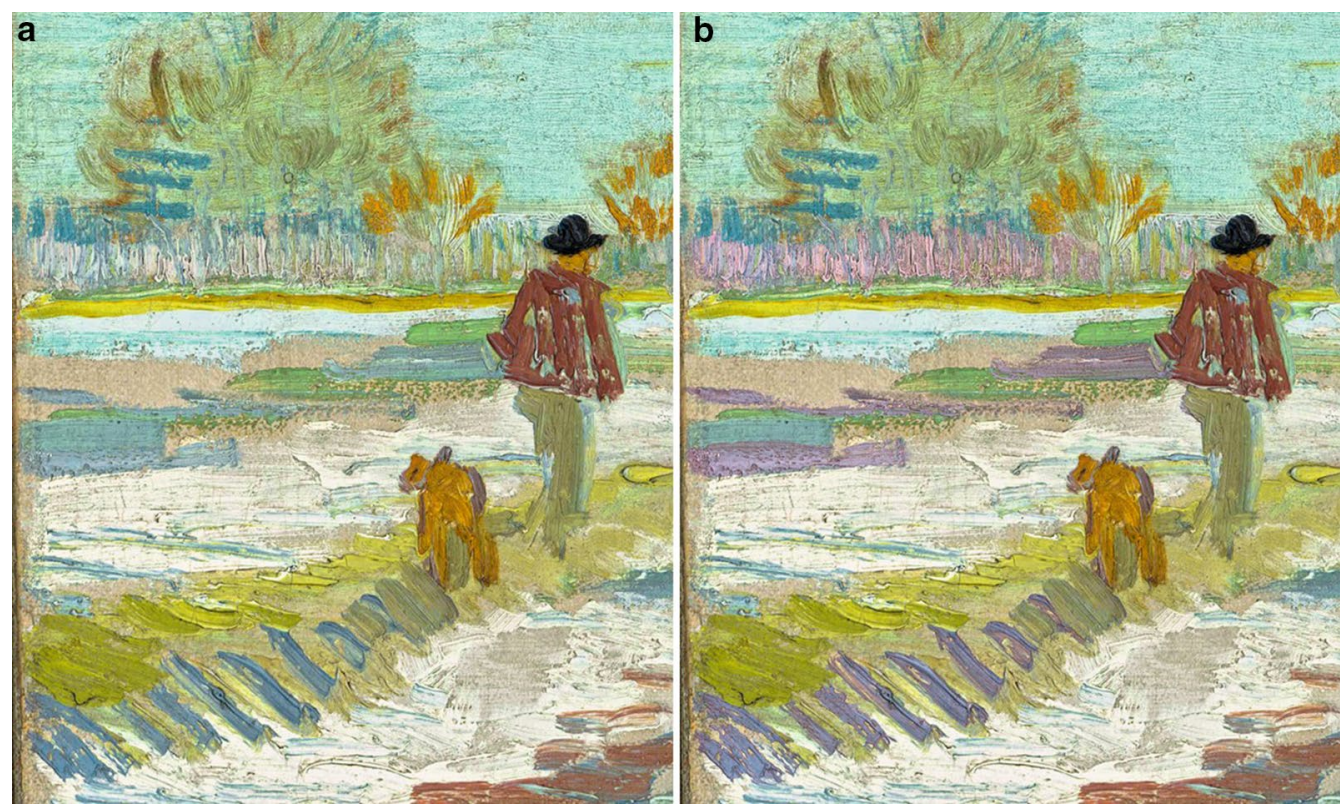

Fig. 8 Detail of the upper left quadrant of Landscape with Snow, showing a current state of painting, and $\mathbf{b}$ a digital recolorized visualization that approximates the original appearance of the faded pinks. Photo: Roy S. Berns ${ }^{\oplus} 2020$ Roy S. Berns 


\section{Mountains at Saint-Rémy (1889)}

At his own behest, in May 1889, Van Gogh entered an asylum for the mentally ill in Saint-Rémy-de-Provence, which is surrounded by an inimitable landscape of geological significance. When he first arrived, the artist painted within the confines of the rooms and grounds of Saint-Paul-de-Mausole. Yet, for a short time over the summer, he began to venture out into the countryside, working in close proximity to Les Alpilles. Mountains at Saint-Rémy (Fig. 1c) was executed in July, probably en plein air, with a view from the base of the dramatic mountain range. In a letter of July 14th or 15 th to his brother Theo, he referred to this Guggenheim painting as follows: "The latest canvas I've done is a view of mountains with a darkish hut among olive trees at the bottom" [49]. A passionate, yet controlled energy characterizes the composition, which mirrors the intensity with which Van Gogh, in his delicate mental state during this period, was questioning the meaning of life and his position within the universe. He described his response to the alpine landscape and the literary influence of Édouard Rod during his summer rehabilitation in another letter to Theo: "...to my taste the dark greens go well with the ochre tones, there's something sad in them that's healthy, and that's why it doesn't annoy me. That's perhaps also the case with the Mountain. People will tell me that mountains aren't like that, and that there are black contours as wide as a finger. But anyway it seemed to me that it expressed the passage in Rod's book [Le sens de la vie, 1889]-one of the very rare passages of his in which I find something goodon a lost land of dark mountains in which one noticed the darkish huts of goatherds, where sunflowers bloomed" [50].

A small hut and garden, the mere hint of a mortal presence, are visible in the foreground of Mountains at SaintRémy. A stroke of red highlights the chimney, and playful dots of impasto, applied over dry paint, form a charming cluster of sunflowers, hollyhocks, and gladioli. Reflecting the artist's mature style, the paint handling comprises stylized swirling forms, thin and thick strokes, and systematic parallel lines adjacent to long undulating veins. Although primarily built up with thick impastoed paint, intermittent skips reveal the ground layer, particularly in the sky and foreground, which is rendered rosy beige by the adjacent blue and green tonalities.

This painting was executed on a coarse plain weave linen, with a thin and warm-toned lead white-based oil ground. Thread counting software analysis applied to a high resolution $\mathrm{X}$-radiograph indicates that the weft direction is horizontal, and that the threads have an average density of 17.6 warp th/cm and 11.3 weft th $/ \mathrm{cm}$, with more significant variation in the weft density. It is interesting to note that this canvas appears very similar in weave and density to that of thirty-six paintings from other collections [Stringari L, Johnson D. Personal communication], most closely matched to Undergrowth (1889, Van Gogh Museum, Amsterdam), with cusping from opposite selvedges on the proper left and proper right of the two canvases [38]. The edges were cut during an early lining, when the painting was mounted on a standard-size French stretcher.

Microscopic examination revealed an underdrawing in dilute blue paint, applied with a brush, which delineated the structure of the rocky landscape. This rough sketch was subsequently filled in with thicker and more deliberate strokes. Beneath the final augmentation of the craggy mountains are bright blues and turquoise green, partially concealed by clay and ocher earthen tones, and a wide array of muted greens and blues. The underlying colors suggest a later reworking of the composition after the paint had partially dried. Thick strokes of lead white at bottom right, evident in the MA-XRF maps, establish the path into the mountains (Fig. 9), with faint streaks of blue, pink, and orange. Examination through a stereomicroscope suggests that passages of pinks and orange hues, still visible through cracks in the paint, have faded in this foreground area.

Curvilinear strokes describe the roiling and tumbling forms in the rocks. Working over a thin underpainting, Van Gogh applied abundant, pure colors that were mixed together on the canvas, resulting in a surface that resembles a tapestry of wide embroidered stitches. Perhaps most striking are the crescent markings that define the bright blue sky, achieved with cobalt blue, emerald green, and zinc white visualized in the cobalt, copper, and zinc MA-XRF maps (Figs. 9 and 10). The sky was painted before inscribing the outlines of the mountains. Wide borders of dark blue demarcate the mountain ridgescalligraphic lines that recall Van Gogh's ink drawings as well as the Japanese wood-block prints he collected. This dark blue paint is most likely Prussian blue, visible in the iron distribution map in Figs. 9 and 10, but some of these lines also contain eosin red, as revealed by the bromine distribution map, indicating that they were intended to be purple. It is likely that other red lakes may have been used throughout the painting, rendering it warmer overall, however further investigations by means of microinvasive techniques would be required to confirm this hypothesis.

\section{Conclusions}

The examination and analysis of three paintings from Vincent van Gogh's s mature years, namely Roadway with Underpass (1887), Landscape with Snow (1888), and Mountains at Saint-Rémy (1889), helped to address authenticity questions and to shed light on the possible 


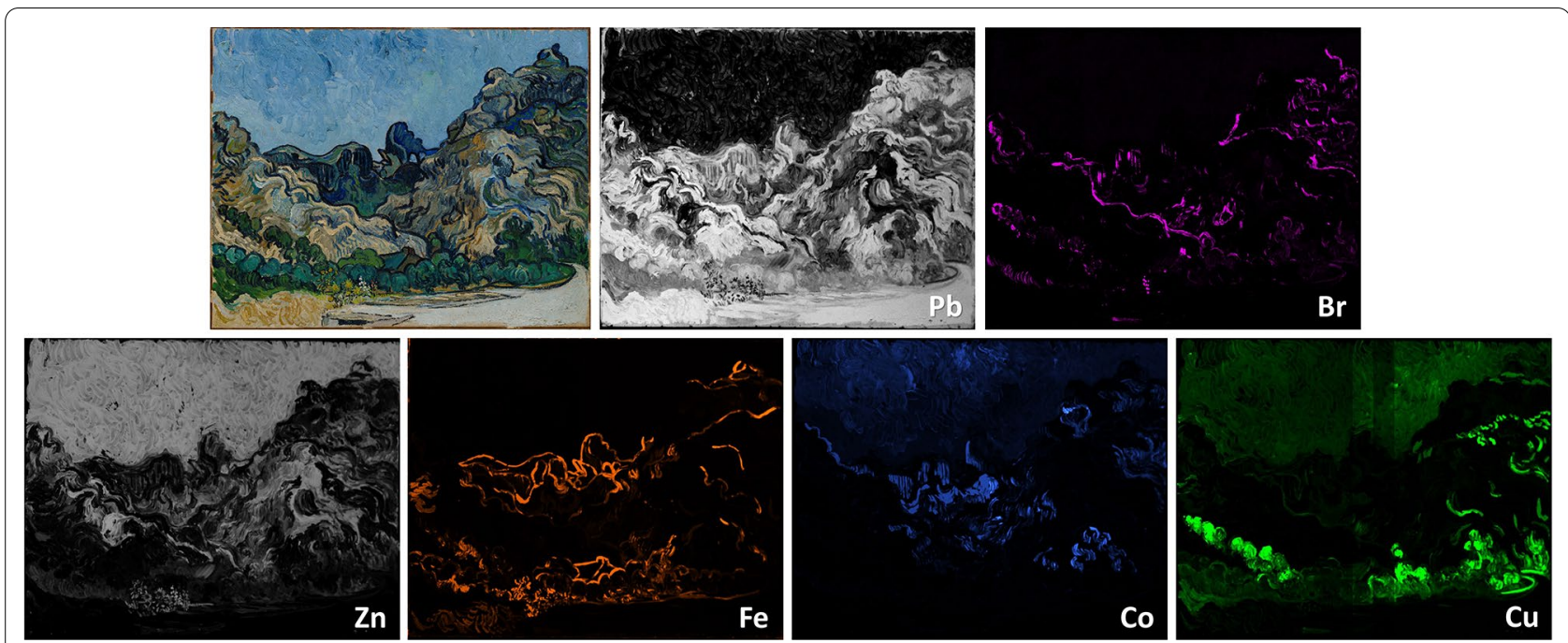

Fig. 9 Elemental distribution maps of Mountains at Saint-Rémy acquired by MA-XRF. From top left to bottom right: lead (Pb L $\beta)$, bromine (Br Ka), zinc (Zn Ka), iron (Fe Ka), cobalt (Co Ka), and copper (Cu Ka)
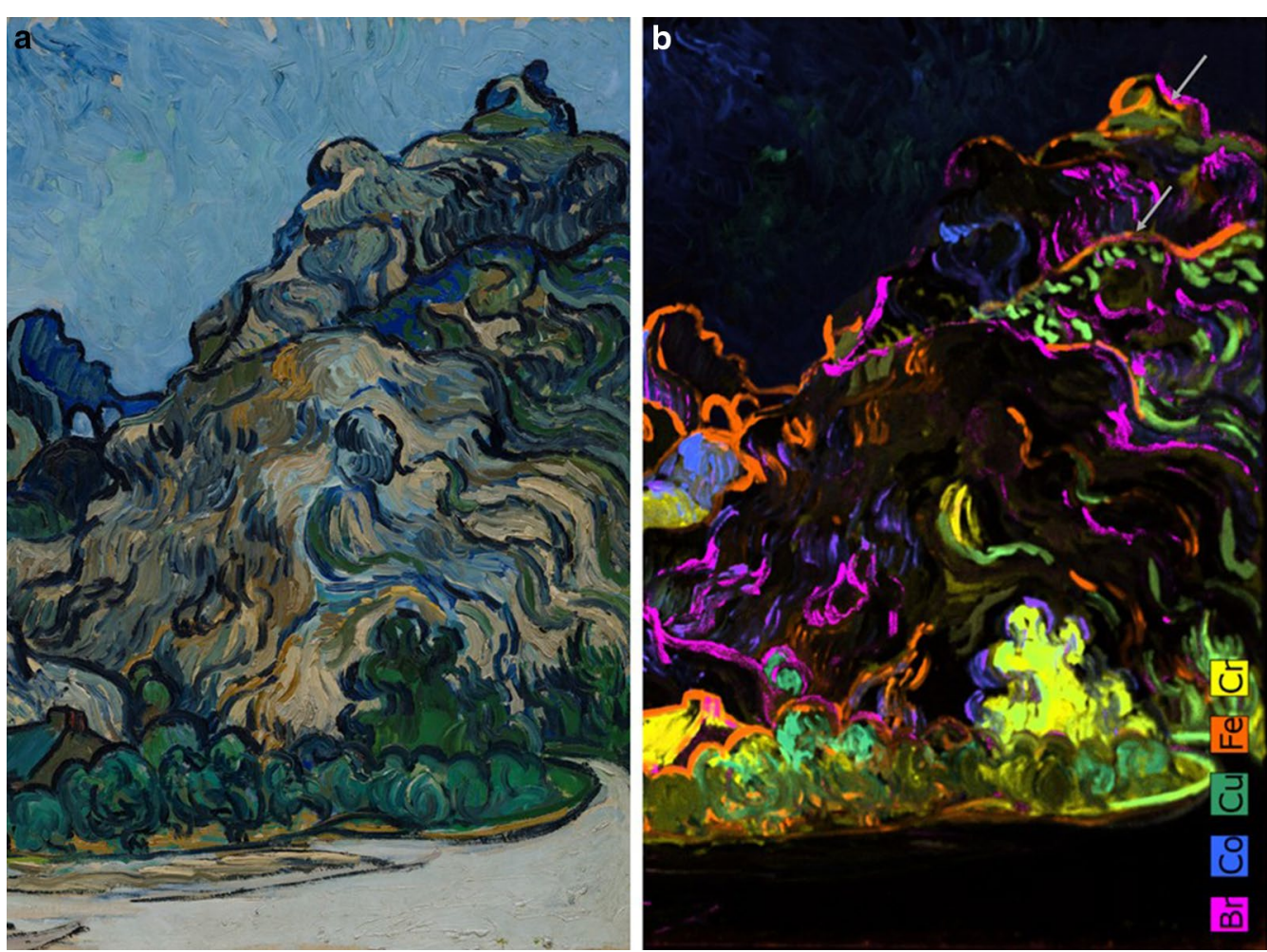

Fig. 10 a Detail of Mountains at Saint-Rémy juxtaposed with b an overlap of the bromine (Br Ka), cobalt (Co Ka), copper (Cu Ka), iron (Fe Ka), and chromium ( $\mathrm{Cr} \mathrm{Ka}$ ) distribution maps acquired by MA-XRF. The gray arrows in the latter image indicate some of the locations where eosin red (Br) and an iron-containing pigment (Fe), likely Prussian blue, were used to outline the mountains 
presence of ongoing degradation phenomena, including color changes. The in-depth investigation of the surface coatings and degradation materials, ground and paint layers, brushwork and paint quality, distribution of colors, structure of the works, and their supports provided crucial information to substantiate art historical research, to aid in the understanding of materials and techniques, and to clarify the current aesthetic appearance of these works, which have undergone conservation treatments and natural deterioration. Furthermore, the extensive scientific analysis supports the design and development of preservation protocols as well as appropriate conservation treatment strategies.

The Wacker forgeries of the late 1920s were often based on the artist's major subjects, such as the olive grove or sunflowers, if not direct copies of authentic works. While Roadway with Underpass and Landscape with Snow are relatively minor paintings within Van Gogh's oeuvre, they document the artist's movements in France at critical junctures in his career. Further, the analysis by a combination of non-invasive and microinvasive tools, along with close visual examination, revealed the use of materials and techniques analogous to contemporaneous and indisputably authentic Van Gogh works. Most notable, for Landscape with Snow, is the close correspondence with the support and ground of View of a Butcher's Shop, a painting made in the first few days following the artist's arrival in Arles. The detection of a stamp from one of Van Gogh's preferred Parisian colorman shop, Tasset et L'Hôte, applied directly to the original support of this 1888 work but hidden beneath an early lining canvas, helped to further place it in the period.

Other salient discoveries included the characterization of faded organic lake pigments, primarily eosin red, which caused a shift of bright pinks to pale pink and white, of purple and violets to blue, and of mauve to gray in Landscape with Snow and Mountains at Saint-Rémy. This identification led to a digital reconstruction of Landscape with Snow, providing viewers with a recolorized visualization to approximate the appearance of the original palette, prior to the fading of the pink and purple tones. For Roadway with Underpass, the characterization of a non-original varnish, of a sulfur-, lead-, and potassium-containing layer between the ground and paint layers, and of metabolite products of a certain genus of fungi-yielding a brownish appearance to the surface and likely indicating biodeterioration-contributed to the development of a suitable treatment for this painting.

\section{Supplementary Information}

The online version contains supplementary material available at https://doi. org/10.1186/s40494-021-00489-1.

Additional file 1: Figure S1. Polarized light microphotographs of cross sections VG1 (top) and VG3 (bottom) from Roadway with Underpass.

Additional file 2: Figure S2. X-ray elemental maps acquired by SEM/ EDS of a portion of cross section VG4 from Roadway with Underpass, i.e. ground preparation and paint. The red arrows indicate the presence of two sulfur-, lead-, and potassium-rich layers. It is possible that the migration of these elements from the adjacent lead white and iron-containing earth paints may have contributed to the formation of the layers observed.

Additional file 3: Figure S3. Detail of Roadway with Underpass, far right, showing dilute red underpainting of the tree trunk, thick impasto, and grainy effect created by the ground (photograph taken after the 2018 varnish removal).

Additional file 4: Figure S4. Detail of Roadway with Underpass before (right) and after (left) cleaning.

Additional file 5: Figure S5. Polarized light microphotographs of cross sections S2 (top), S3 (middle), and S6 (bottom) from Landscape with Snow.

Additional file 6: Figure S6. (A) Raman and (B) FTIR spectra of sample S2 from Landscape with Snow, i.e. a scraping of canvas and ground. Materials identified include lead white in the form of hydrocerussite, lead carboxylates, and an organic medium.

Additional file 7: Figure S7. Elemental distribution maps of Landscape with Snow acquired by MA-XRF. From top left to bottom right: lead $(\mathrm{Pb} L \beta)$, zinc (Zn Ka), chromium (Cr Ka), cobalt (Co Ka), copper (Cu Ka), iron (Fe Ka), and mercury ( $\mathrm{Hg} \mathrm{La})$.

Additional file 8: Figure S8. X-ray elemental maps and BSE image acquired by SEM/EDS of a portion of cross section $\mathrm{S} 7$ from Landscape with Snow, i.e. ground preparation and paint, revealing that the latter consists of a bromine-containing pigment, most likely eosin red, precipitated onto an aluminum-based substrate, mixed with lead white and an abundance of minute ultramarine blue particles.

\section{Abbreviations}

IR photography: Infrared photography; UV photography: Ultraviolet photography; XRF: X-ray fluorescence spectroscopy; MA-XRF: Macro-X-ray fluorescence spectroscopy; FTIR: Fourier-transform infrared spectroscopy; SEM/EDS: Scanning electron microscopy with energy-dispersive X-ray spectroscopy; BSE: Back-scattered electron; HPLC-PDA: High-performance liquid chromatography with photodiode array detection; Py-GC/MS: Pyrolysis-gas chromatography/ mass spectrometry.

\section{Acknowledgements}

The authors are grateful to Charlotte Hale, Paintings Conservator at The Met, for many helpful discussions and for assisting in setting up the paintings for MA-XRF analysis. Dr. Ella Hendriks, University of Amsterdam, generously shared her deep knowledge of Van Gogh's work and was an invaluable research partner. Kathrin Pilz, Paintings Conservator at the Van Gogh Museum, Amsterdam, also facilitated comparative study and analysis, and the authors likewise appreciate the additional research support from Neinke Bakker, Monique Hageman, Teio Meedendorp, and Louis van Tilborgh, also Van Gogh Museum. Hillary Torrence, Manager, Conservation, Solomon R. Guggenheim Museum, coordinated many facets of this Van Gogh study at the Guggenheim. FP would also like to acknowledge Dr. Anna Cesaratto for her contribution to this project during her time at The Met working in the NICS program.

\section{Authors' contributions}

FP coordinated the study, removed samples, prepared cross sections, carried out optical microscopy, point XRF, FTIR, Raman, Py-GC/MS, as well as part of SEM/EDS analysis and data interpretation, and wrote the manuscript draft with inputs from all other authors. EB conducted some of the SEM/EDS analysis and data interpretation. NS performed HPLC-PDA analysis and data 
interpretation. LMS acquired the MA-XRF data and contributed to the data processing and interpretation. SAC contributed to the MA-XRF data processing and interpretation, as well as to the interpretation of micro-analytical data. RB carried out visible reflection spectroscopy and multi-channel visible spectrum four-light imaging, and created the digital recolorized visualization of Landscape with Snow. MF and LS provided art historical context, treatment information, data from IR and UV photography, X-radiography, microscopic examination of the paintings, and supported the scientific work. All authors edited the manuscript and approved the final version.

\section{Funding}

This research was made possible by the Network Initiative for Conservation Science (NICS), a Metropolitan Museum of Art program. Support for NICS was provided by a grant (31500630) from The Andrew W. Mellon Foundation. During the period of research, LMS was supported by an Andrew W. Mellon Fellowship in The Met's DSR.

\section{Availability of data and materials}

All data generated during this study are either included in this published article or available from the corresponding author upon reasonable request.

\section{Competing interests}

The authors declare that they have no competing interests.

\section{Author details}

${ }^{1}$ Department of Scientific Research, The Metropolitan Museum of Art, 1000 Fifth Avenue, New York, NY 10028, USA. ${ }^{2}$ Cornell High Energy Synchrotron Source, Synchrotron Drive, Ithaca, NY 14853, USA. ${ }^{3}$ Program of Color Science, Rochester Institute of Technology, 54 Lomb Memorial Drive, Rochester, NY 14623, USA. ${ }^{4}$ Departments of Curatorial and Conservation, Solomon R. Guggenheim Museum, 1071 Fifth Avenue, New York, NY 10128, USA.

\section{Received: 29 October 2020 Accepted: 23 January 2021}

Published online: 01 February 2021

\section{References}

1. Hendriks E, Van Tilborgh L. Van Gogh's 'Garden of the Asylum': genuine or fake? Burlingt Mag. 2001;143(1176):145-56.

2. Burnstock A, Lanfear I, van den Berg KJ, Carlyle L, Clarke M, Hendriks E, Kirby J. Comparison of the fading and surface deterioration of red lake pigments in six paintings by Vincent van Gogh with artificially aged paint reconstructions. In: Vergier I, editor. Proceedings of the 14th Triennial Meeting of the ICOM Committee for Conservation Meeting in Den Haag, Preprint book I. London: James and James; 2005. p. 459-66.

3. van Bommel M, Geldof M, Hendriks E. An investigation of organic red pigments used by Vincent van Gogh (November 1885 to February 1888). Art Matters. 2005;3:111-37.

4. Geldof M, de Keijzer M, van Bommel M, Pilz K, Salvant J, van Keulen H, Megens L. Van Gogh's geranium lake. In: Vellekoop M, Geldof M, Hendriks E, Jansen L, de Tagle A, editors. Van Gogh's studio practice. Brussels: Mercatorfonds; 2013. p. 268-89.

5. Geldof M, Megens L, Salvant J. Van Gogh's palette in Arles, Saint-Rémy and Auvers-sur-Oise. In: Vellekoop M, Geldof M, Hendriks E, Jansen L, de Tagle A, editors. Van Gogh's studio practice. Brussels: Mercatorfonds; 2013. p. 238-55.

6. Groom G, editor. Van Gogh's bedrooms. Chicago: The Art Institute of Chicago; 2016.

7. Centeno SA, Hale C, Carò F, Cesaratto A, Shibayama N, Delaney J, Dooley K, van der Snickt G, Janssens K, Stein SA. Van Gogh's Irises and Roses: the contribution of chemical analyses and imaging to the assessment of color changes in the red lake pigments. Her Sci. 2017;5(1):18.

8. Kirchner E, van der Lans I, Ligterink F, Geldof M, Proano Gaibor AN, Hendriks E, Janssens K, Delaney J. Digitally reconstructing van Gogh's Field with Irises near Arles part 2: Pigment concentration maps. Color Res Appl. 2017:43(2):158-76.

9. Fieberg JE, Knutås P, Hostettler K, Smith GD. "Paintings fade like flowers": pigment analysis and digital reconstruction of a faded pink lake pigment in Vincent van Gogh's Undergrowth with Two Figures. Appl Spectrosc. 2017;71(5):794-808
10. Dooley KA, Chieli A, Romani A, Legrand S, Miliani C, Janssens K, Delaney JK. Molecular fluorescence imaging spectroscopy for mapping low concentrations of red lake pigments: Van Gogh's painting The Olive Orchard. Angew Chem Int Ed. 2020;132(15):6102-9.

11. Alvarez-Martin A, Cleland TP, Kavich GM, Janssens K, Newsome GA. Rapid evaluation of the debromination mechanism of eosin in oil paint by direct analysis in real time and direct infusion-electrospray ionization mass spectrometry. Anal Chem. 2019;91(16):10856-63.

12. Chieli A, Miliani C, Degano I, Sabatini F, Tognotti P, Romani A. New insights into the fading mechanism of Geranium lake in painting matrix. Dyes Pigm. 2020;108:600.

13. Sabatini F, Eis E, Degano I, Thoury M, Bonaduce I, Tenorio AL. The issue of eosin fading: a combined spectroscopic and mass spectrometric approach applied to historical lakes. Dyes Pigm. 2020;108:436.

14. Monico L, Snickt G, Janssens K, Nolf W, Miliani C, Dik J, Radepont M, Hendriks E, Geldof M, Cotte M. Degradation process of lead chromate in paintings by Vincent van Gogh studied by means of synchrotron X-ray spectromicroscopy and related methods. 2. Original paint layer samples. Anal Chem. 2011:83(4):1224-31.

15. Monico L, Janssens K, Miliani C, Brunetti BG, Vagnini M, Vanmeert F, Falkenberg G, Abakumov A, Lu Y, Tian H, Verbeeck J. Degradation process of lead chromate in paintings by Vincent van Gogh studied by means of spectromicroscopic methods. 3. Synthesis, characterization, and detection of different crystal forms of the chrome yellow pigment. Anal Chem. 2013:85(2):851-9

16. Monico L, Janssens K, Miliani C, Van der Snickt G, Brunetti BG, Cestelli Guidi M, Radepont M, Cotte M. Degradation process of lead chromate in paintings by Vincent van Gogh studied by means of spectromicroscopic methods. 4. Artificial aging of model samples of co-precipitates of lead chromate and lead sulfate. Anal Chem. 2013;85(2):860-7.

17. Monico L, Janssens K, Cotte M, Sorace L, Vanmeert F, Brunetti BG, Miliani C. Chromium speciation methods and infrared spectroscopy for studying the chemical reactivity of lead chromate-based pigments in oil medium. Microchem J. 2016;124:272-82.

18. Der RG. Fall Wacker Kunst und Künstler. 1932;31(5):153-65.

19. W Feilchenfeldt. Van Gogh fakes: the Wacker affair, with an illustrated catalogue of the forgeries. Simiolus. 1989;19(4):289-316.

20. Feilchenfeldt W. By appointment only: Cezanne, Van Gogh and some secrets of art dealing. New York: Thames and Hudson; 2006. p. 81-97.

21. Koldehoff S. The Wacker forgeries: a catalogue. Van Gogh Museum J. 2002;54:138-49.

22. Faille JB. Sammler und Markt: Unbekannte bilder van Vincent van Gogh. Der Cicerone. 1927;19(3):105-05.

23. Koldehoff S. Marketing modernism: the Thannhauser Gallery and its clients. In: Koldehoff S, Stolwijk C, editors. The Thannhauser Gallery: Marketing Van Gogh. Brussels: Mercatorfonds; 2017. p. 67-9.

24. Hans Bammann to Justin Thannhauser, June 10 and June 27, 1932, Galerien Thannhauser Archive, ZADIK, Cologne.

25. Vincent van Gogh, Arles, to Theo van Gogh, ca. May 20, 1888, letter 611. In Jansen L, Luijten H, Bakker N, editors. Vincent van Gogh: the letters; the complete illustrated and annotated edition, vol. 4. London: Thames and Hudson; 2009. p. 86-87.

26. Berns R, Taplin L, Nezamabadi M. Spectral imaging using a commercial colour-filter array digital camera. In: Bridgland J, editor. Preprints for the ICOM-CC 14th Triennial Meeting, The Hague, vol. 2. London: James and James; 2005. p. 743-50.

27. Berns RS, Chen T. Practical total appearance imaging of paintings. IS\&T Archiving. 2012;9:162-7.

28. Cox BD, Berns RS. Imaging artwork in a studio environment for computer graphics rendering. IS\&T/SPIE Electron Imag. 2015;9398:939803.

29. Wouters J, Verhecken A. The coccid insect dyes: HPLC and computerized diode-array analysis of dyed yarns. Stud Conserv. 1989;34:189-200.

30. Stringari L. Materials and Process. In: Fontanella M, editor. Thannhauser Collection: French Modernism at the Guggenheim. New York: Guggenheim Museum Publications; 2018. p. 234-7.

31. Fontanella M, Stringari L. Amending the Record: Vincent van Gogh's Roadway with Underpass and Landscape with Snow. In: Fontanella M, editor. Thannhauser Collection: French Modernism at the Guggenheim. New York: Guggenheim Museum Publications; 2018. p. 242-7.

32. Hendriks E, Tilborgh L. Vincent van Gogh Paintings. Antwerp \& Paris, 1885-1888, vol. 2. Zwolle: Waanders Publishers; 2011. 
33. Price SW, Van Loon A, Keune K, Parsons AD, Murray C, Beale AM, Mosselmans JF. Unravelling the spatial dependency of the complex solidstate chemistry of $\mathrm{Pb}$ in a paint micro-sample from Rembrandt's Homer using XRD-CT. Chem Comm. 2019;55(13):1931-4.

34. Nielsen KF, Thrane U, Larsen TO, Nielsen PA, Gravesen S. Production of mycotoxins on artificially inoculated building materials. Int Biodeter Biodegrad. 1998:42(1):9-16.

35. Sterflinger K, Piñar G. Microbial deterioration of cultural heritage and works of art—tilting at windmills? Appl Microbiol Biotechnol. 2013;97(22):9637-46.

36. Van Gogh letter 569: Jansen L, Luijten H, Bakker N, editors. Vincent van Gogh - The Letters. Amsterdam \& The Hague: Van Gogh Museum \& Huygens ING; 2009. Version: October 2020. http://vangoghletters.org. Accessed 8 Jan 2021.

37. Van Gogh letter 579: Jansen L, Luijten H, Bakker N, editors. Vincent van Gogh - The Letters. Amsterdam \& The Hague: Van Gogh Museum \& Huygens ING; 2009. Version: October 2020. http://vangoghletters.org. Accessed January 8, 2021

38. Johnson Jr CR, Hendriks E, Noble P, Franken M. Advances in computerassisted canvas examination: Thread counting algorithms. In: 37th Annual Meeting of American Institute for Conservation of Historic and Artistic Works, Los Angeles, California, May 21st, 2009. p. 30

39. Gettens RJ, FitzHugh EW, Feller RL. Calcium carbonate whites. Stud Conserv. 1974;19(3):157-84.

40. Reischig P, Helfen L, Wallert A, Baumbach T, Dik J. High-resolution noninvasive 3D imaging of paint microstructure by synchrotron-based $X$-ray laminography. Appl Phys A. 2013;111(4):983-95.

41. Antunes V, Candeias A, Coroado J, Serrão V, Cachão M, Carvalho ML. A multidisciplinary approach to the study of the brightening effects of white chalk ground layers in 15th and 16th century paintings. Anal Methods. 2016:8(24):4785-97.

42. Haswell R, Carlyle L, Mensch KT. Van Gogh's painting grounds: quantitative determination of bulking agents (extenders) using SEM/EDX. Microchim Acta. 2006;155(1-2):163-7.

43. Stols-Witlox M. Grounds, 1400-1900. In: Stoner JH, Rushfield Routledge $\mathrm{R}$, editors. Conservation of easel paintings. London: Routledge; 2012. p. 161-85.
44. Van Gogh letter 593: Jansen L, Luijten H, Bakker N, editors. Vincent van Gogh - The Letters. Amsterdam \& The Hague: Van Gogh Museum \& Huygens ING; 2009. Version: October 2020. http://vangoghletters.org. Accessed 8 Jan 2021.

45. Van Gogh letter 590: Jansen L, Luijten H, Bakker N, editors. Vincent van Gogh - The Letters. Amsterdam \& The Hague: Van Gogh Museum \& Huygens ING; 2009. Version: October 2020. http://vangoghletters.org. Accessed 8 Jan 2021.

46. Berns RS. Digital color reconstructions of cultural heritage using colormanaged imaging and small-aperture spectrophotometry. Color Res Appl. 2019;44:531-46.

47. Imai FH, Rosen MR, Berns RS. Multi-spectral imaging of a van Gogh's self-portrait at the National Gallery of Art, Washington DC. In: Society for imaging science and technology conference proceedings; 2001. p. 185-89.

48. Van Gogh letter 595: Jansen L, Luijten H, Bakker N, editors. Vincent van Gogh - The Letters. Amsterdam \& The Hague: Van Gogh Museum \& Huygens ING; 2009. Version: October 2020. http://vangoghletters.org. Accessed 8 Jan 2021.

49. Van Gogh letter 789: Jansen L, Luijten H, Bakker N, editors. Vincent van Gogh - The Letters. Amsterdam \& The Hague: Van Gogh Museum \& Huygens ING; 2009. Version: October 2020. http://vangoghletters.org. Accessed 8 Jan 2021.

50. Van Gogh letter 805: Jansen L, Luijten H, Bakker N, editors. Vincent van Gogh - The Letters. Amsterdam \& The Hague: Van Gogh Museum \& Huygens ING; 2009. Version: October 2020. http://vangoghletters.org. Accessed 8 Jan 2021.

\section{Publisher's Note}

Springer Nature remains neutral with regard to jurisdictional claims in published maps and institutional affiliations.

\section{Submit your manuscript to a SpringerOpen ${ }^{\circ}$ journal and benefit from:}

- Convenient online submission

- Rigorous peer review

- Open access: articles freely available online

- High visibility within the field

- Retaining the copyright to your article

Submit your next manuscript at $\boldsymbol{\nabla}$ springeropen.com 